\title{
Seguimiento al análisis de las edificaciones de uso escolar: su evaluación e impacto en la educación primaria y secundaria
}

\begin{abstract}
Follow-up to the analysis of buildings for school use: their evaluation and impact on primary and secondary education
\end{abstract}

Acompanhamento da análise de edificações para uso escolar: sua avaliação e impacto no ensino fundamental e médio

\author{
Nancy Jacqueline Pacheco Martínez \\ Centro de Estudios e Investigaciones para el Desarrollo Docente A. C., México \\ nancyv9@yahoo.com.mx \\ https://orcid.org/0000-0001-8621-8921
}

\section{Resumen}

El objetivo del presente artículo consistió en dar seguimiento a la metodología aplicada por Pacheco (2021) para conocer la situación en que se encontraba la infraestructura de instituciones educativas del nivel preescolar, aunque en esta ocasión se eligió a 17 planteles de educación básica ubicados en la zona centro del país (Ciudad de México, Hidalgo, Querétaro y Tlaxcala). Para ello, se realizó un estudio de carácter cuantitativo, así como cualitativo con soporte fotográfico, levantamiento físico de datos específicos de cada plantel, así como análisis de los indicadores de la Secretaría de Educación Pública (SEP). Las preguntas que orientaron este estudio fueron las siguientes: 1) ¿el número de profesores disponibles es suficiente para brindar una educación de calidad a toda la población estudiantil?,2) ¿la infraestructura física de las escuelas es apta para la edad de sus usuarios?, 3) ¿los espacios físicos usados para las actividades académicas cumplen con los requerimientos básicos para desarrollarlas con eficacia?, y 4) ¿los planteles educativos cuentan con las condiciones de infraestructura adecuadas para operar de manera segura en medio de la actual situación generada por la pandemia de covid-19? Los resultados demuestran las carencias generales de los planteles examinados en cuanto a ventilación, iluminación, mobiliario y recursos hidrosanitarios. En conclusión, se puede indicar que este escenario, en medio de la actual 


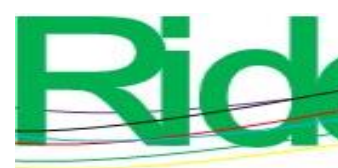

Revista Iberoamericana para la
Investigación y el Desarrollo Educativo
ISSN $2007-7467$

emergencia generada por la covid-19, dificulta el regreso a clases presenciales, pues los planteles necesitan cumplir con un mínimo de condiciones de bioseguridad para llevar a cabo con éxito el proceso educativo.

Palabras clave: ambiente educacional, cumplimiento normativo, edificaciones de uso escolar, educación primaria y secundaria, relación alumno-profesor.

\section{Abstract}

The objective of this article consisted of following up on the methodology applied by Pacheco (2021) to know the situation in which the infrastructure of educational institutions of the preschool level was found, although on this occasion 17 elementary schools located in the central area of the country (Mexico City, Hidalgo, Querétaro and Tlaxcala). For this, a quantitative study was carried out, as well as a qualitative one with photographic support, physical survey of specific data of each campus, as well as analysis of the indicators of the Ministry of Public Education (SEP). The questions that guided this study were the following: 1) Is the number of teachers available enough to provide a quality education to the entire student population? 2) Is the physical infrastructure of the schools suitable for the age of its users? 3) Do the physical spaces used for academic activities meet the basic requirements to develop them effectively? And 4) Do educational establishments have adequate infrastructure conditions to operate safely in the midst of the current situation generated by the covid-19 pandemic? The results show the general deficiencies of the schools examined in terms of ventilation, lighting, furniture and hydrosanitary resources. In conclusion, it can be indicated that this scenario, in the midst of the current emergency generated by covid-19, makes it difficult to return to face-to-face classes, since the schools need to comply with a minimum of biosafety conditions to carry out the process successfully educational.

Keywords: educational environment, regulatory compliance, buildings for school uses, primary and secondary education, student-teacher relationship. 


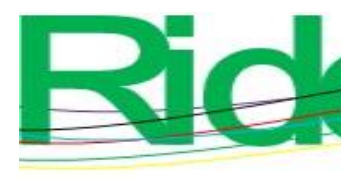

Revista Iberoamericana para la Investigación y el Desarrollo Educativo ISSN 2007-7467

\section{Material y método}

Se realizó un estudio de carácter cuantitativo, así como cualitativo con soporte fotográfico, levantamiento físico de datos específicos de cada plantel para su posterior estudio, así como análisis de los indicadores de la Secretaría de Educación Pública (SEP). Asimismo, la investigación tuvo un carácter multidisplinario al estudiar el cumplimiento normativo, ya que se requirieron conocimientos en materia cívica, estudios arquitectónicos, certidumbre constructiva, instalaciones hidrosanitarias y eléctricas, así como nociones jurídicas. Además, se necesitó la aplicación de normatividad de cumplimiento obligatorio, así como de observancia voluntaria, leyes y reglamentos de construcción según el municipio donde se hallaba el plantel evaluado.

Al ser una continuación del trabajo de Pacheco (2021), se utilizaron las siguientes fases con la finalidad de obtener la replicabilidad de la metodología:

\section{Fase I}

Recopilación de datos de las edificaciones de usos escolar. Esto se efectuó con base en el formato de la cédula de información técnica (CIT) del Instituto de la Infraestructura Física Educativa (INIFED, 2019), y abarcó los siguientes aspectos:
A. Información general del edificio educativo.
B. Localización, entorno e identificación de amenazas.
C. Requerimientos básicos del predio donde está ubicado el plantel.
D. Verificación de que cuente con los siguientes servicios: agua potable, drenaje sanitario-
pluvial, energía eléctrica, instalación de gas, tecnología de la información y comunicación.
E. Accesibilidad.

\section{Fase II}

Cálculo del indicador de la Secretaría de Educación Pública (SEP) (2019) que vinculó el número de estudiantes y de docentes en los edificios de uso escolar. Se identificaron las condiciones elementales e imperiosas con las que deben cumplir las escuelas, según lo establecido por la Organización para la Cooperación y el Desarrollo Económicos (OCDE): accesibilidad, medio ambiente sostenible y colaboración social. Asimismo, se presentaron imágenes que soportaron y validaron la evidencia analizada. 


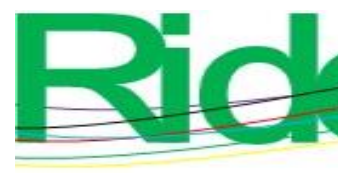

Revista Iberoamericana para la
Investigación y el Desarrollo Educativo
ISSN $2007-7467$

Fase III

Se utilizó la siguiente normatividad aplicada a las escuelas tanto de educación primaria como de secundaria:

a) NMX-R-021-SCFI-2013. Requisitos. Escuelas — calidad de la infraestructura física educativa (Norma Mexicana, 2013).

b) NOM 001 SEDE 2012 Instalaciones Eléctricas (DOF, 2014).

c) NMX-R-084-SCFI-2015. Levantamiento de datos para el diagnóstico de la infraestructura física educativa (Norma Mexicana, 2015a).

d) NMX-R-024-SCFI-2015. Escuelas — supervisión de obra de la infraestructura física educativa (Norma Mexicana, 2015b).

e) NMX-R-90-SCFI-2016. Elementos para la accesibilidad a los espacios de la infraestructura física educativa (Norma Mexicana, 2016).

f) NMX-R-083-SCFI-2019. Escuelas —diseño-fabricación de mobiliario para la infraestructura física educativa - criterios y requisitos (Norma Mexicana, 2019).

g) Normas y especificaciones para estudios, proyectos, construcción e instalaciones (INIFED, 2014).

h) Normas técnicas complementarias al Reglamento de Construcciones de la Ciudad de México (Gaceta Oficial de la Ciudad de México, 2017).

i) Normas Técnicas de la Ley de la Construcción del Estado de Tlaxcala (Norma Mexicana, 2018).

j) Reglamento de Construcciones para el Distrito Federal (Gaceta Oficial del D. F., 2004).

k) Reglamento de Construcciones de Hidalgo.

1) Reglamento de Construcciones de Querétaro.

\section{Datos}

Se consideró una muestra representativa de la zona centro del país de 17 planteles de educación básica, ubicados en los estados de Ciudad de México (CDM), Hidalgo (HGO), Querétaro (QRO) y Tlaxcala (TLAX). A continuación, la tabla 1 muestra las características de las escuelas analizadas: 
Tabla 1. Características básicas de las escuelas analizadas.

\begin{tabular}{|c|c|c|}
\hline Nivel educativo & Clave de centro de trabajo & Ubicación \\
\hline Primaria & P-15EPRO6XXX & Ciudad de México \\
\hline Primaria & P-15EPR21XXX & Ciudad de México \\
\hline Primaria & P-09PPR14XXX & Ciudad de México \\
\hline Primaria & P-09DPR15XXX & Ciudad de México \\
\hline Primaria & P-09DPR28XXX & Ciudad de México \\
\hline Primaria & P-15EPR48XXX & Ciudad de México \\
\hline Primaria & P-09DPR16XXX & Hidalgo \\
\hline Primaria & P-15DPR16XXX & Querétaro \\
\hline Primaria & P-22DPR08XXX & Querétaro \\
\hline Primaria & P-22DPR45XXX & Tlaxcala \\
\hline Primaria & P-29DPR04XXX & Ciudad de México \\
\hline Secundaria & S-09DES00XXX & Ciudad de México \\
\hline Secundaria & S-09DES00XXX & Ciudad de México \\
\hline Secundaria & S-09DES00XXX & Ciudad de México \\
\hline Secundaria & S-09DES00XXX & Ciudad de México \\
\hline Secundaria & S-09DES00XXX & S-09DES00XXX \\
\hline Secundaria & Ciudad de México \\
\hline
\end{tabular}

Nota: Elaboración propia con fines didácticos

\section{Herramientas de campo y análisis}

A. Se revisó el estado actual de la INFE de primaria y secundaria públicas en la zona central de la Ciudad de México. Esta elección se hizo para realizar la comparativa, así como su cumplimiento normativo.

B. Se capturaron digitalmente todas las fichas de recopilación de información de las edificaciones escolares con base en el formato de la cédula de información técnica (CIT) del Instituto de la Infraestructura Física Educativa (INIFED) (2019).

C. Los criterios de suficiencia que usamos para el presente análisis fueron los siguientes:

i. Planteles creados para uso educativo. Aquí se tomó en cuenta la edad del inmueble y si había sido construido como edificio educativo o si fue una adaptación de una casa, habitación, bodega o terreno adaptado sin el cumplimiento mínimo de la normativa. 


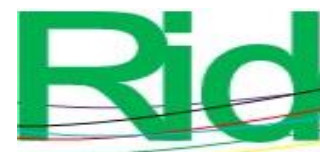

Revista Iberoamericana para la
Investigación y el Desarrollo Educativo
ISSN $2007-7467$

ii. Planteles que cumplen con los requisitos mínimos de uso, solicitados por la OCDE.

iii. Número de escuelas que cuentan con evidencia de un proyecto arquitectónico y planeación general con base en la demanda o proyecto ejecutivo.

iv. Si se cuenta con el mobiliario o equipo mínimo necesario de acuerdo al nivel analizado.

V. Si el plantel tiene los servicios básicos necesarios para prestar su servicio.

vi. Las instalaciones eléctricas e hidrosanitarias son las mínimas necesarias y las adecuadas para el nivel.

vii. Si está ubicado en zona segura (cerca de gasolineras, vías rápidas de transporte, laderas, basureros, mercados, líneas de alta tensión, etc.).

viii. Las áreas administrativas comunes cuentan con ventilación e iluminación según la normatividad requerida por nivel analizado.

D. Se llevó a cabo una revisión bibliográfica para elaborar un mapeo de las principales normativas (de observancia obligatoria y voluntaria) aplicables a la INFE en diversos ámbitos (medio ambiente, protección civil, instalaciones, etc.) en México con el fin de identificar si atienden las necesidades de las escuelas de primaria y secundaria.

\section{Procedimiento}

El estudio fue estructurado con base en las etapas aplicadas en la investigación de Pacheco (2021), ver la figura 1, la cual indica la explicación de las fases de estudio. 


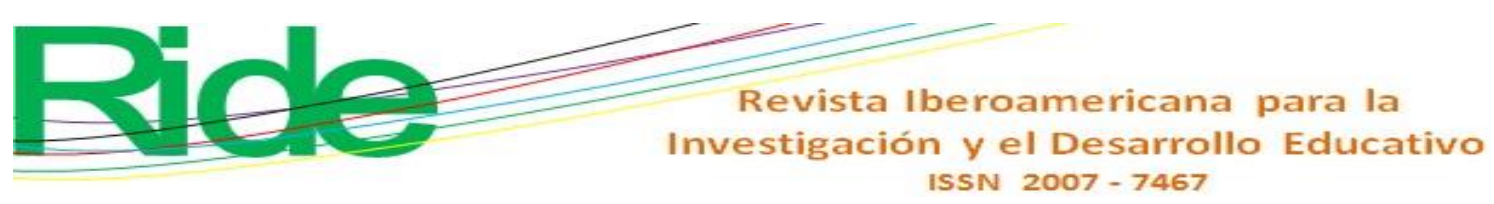

Figura 2. Escuela primaria influenciada en la obra de Juan O`Gorman. Ubicada en Ciudad de México, muestra claros amplios en sus fachadas para el adecuado aprovechamiento de la luz y la ventilación (Xochimilco Tlalpan).

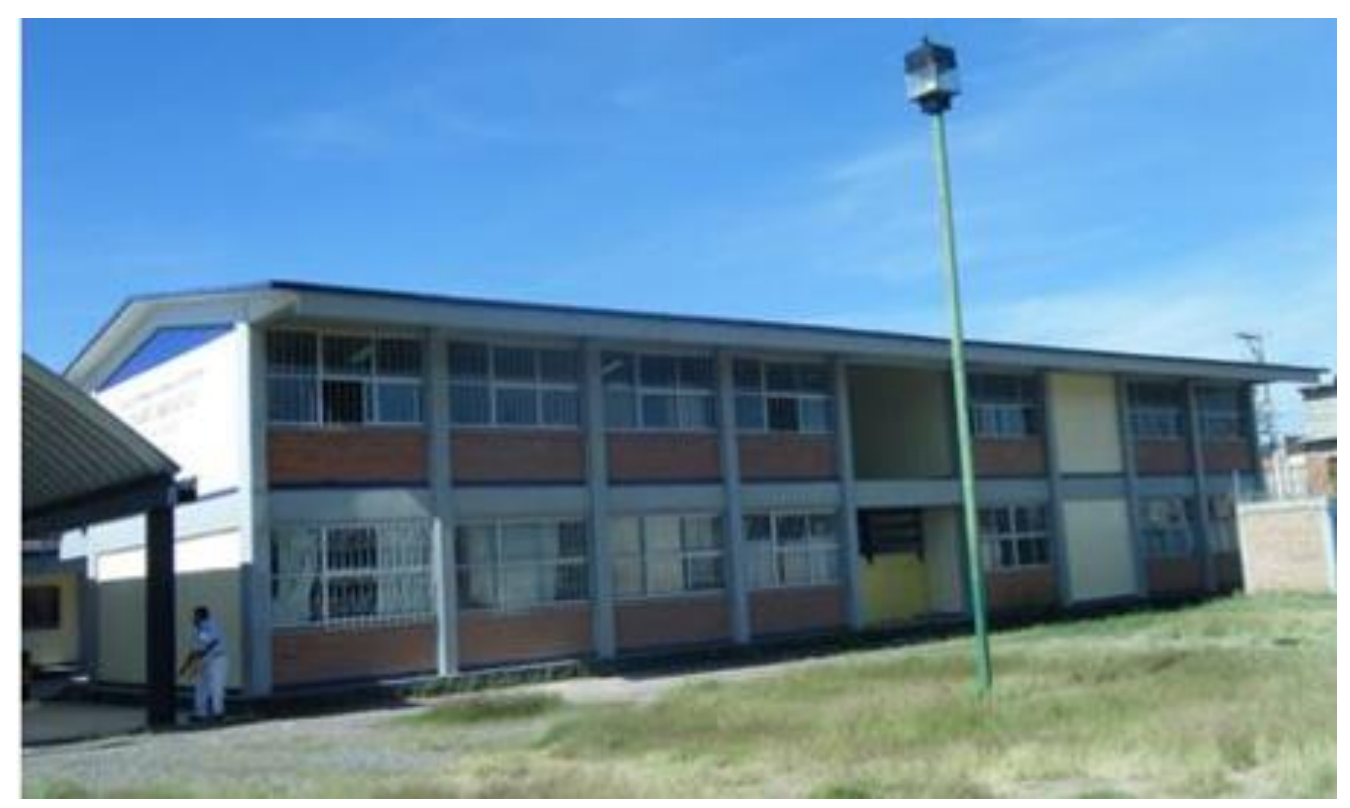

Fuente: Nancy Pacheco (2018) tomada con fines didácticos

Figura 3. Escuela secundaria influenciada en la obra de Juan $\mathrm{O}^{`} \mathrm{Gorman}$. Ubicada en Ciudad de México, cuenta con amplios ventanales para la adecuada ventilación, así como aprovechamiento de la luz natural (Azcapotzalco).

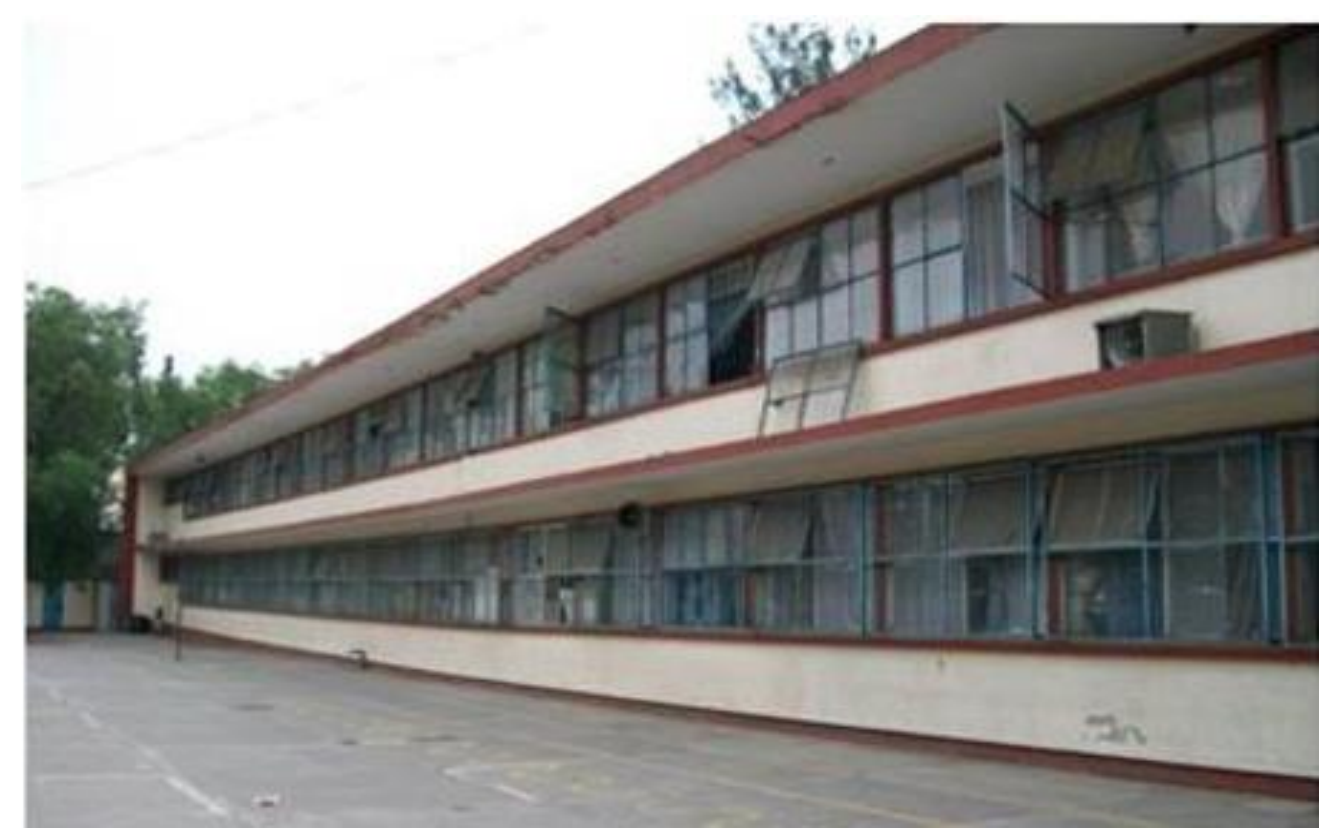

Fuente: Nancy Pacheco (2018) tomada con fines didácticos 

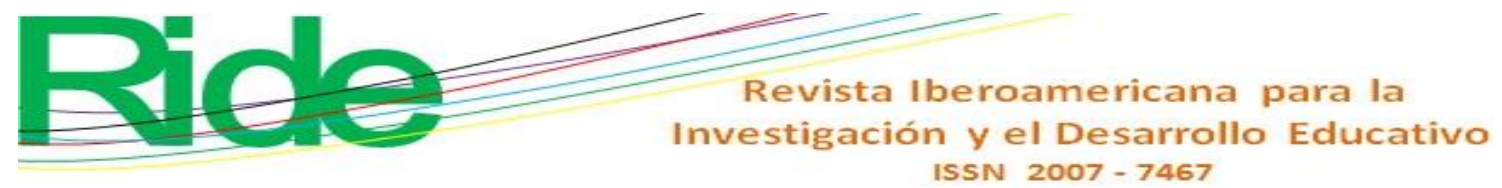

Sin embargo, debido a las acciones emprendidas desde 2012 por la Secretaría de Educación Pública (p. ej., la Reforma Educativa, la Ley General de Educación [LGE], [2019], la actualización de los planes y programas de estudio, así como de los materiales y métodos educativos), dichas infraestructuras no satisfacen las necesidades básicas de los educandos.

En tal sentido, los resultados recabados presentan carencias graves, pues ya no existen las amplias ventanas para aprovechar la luz y la ventilación natural. En su lugar, ahora se levantaron bardas por inseguridad, se obstaculizaron con elementos artificiales del entorno o se eliminaron para ampliar otras áreas colindantes requeridas por la gran cantidad de estudiantes. Además, algunas de esas ventanas limitan con basureros, bardas de casas de habitación, vías rápidas, gasolineras o zonas vandálicas; ver (figuras 4 y 5).

Figura 4. Escuela secundaria ubicada en Ciudad de México, en la localidad de Tláhuac.

Obsérvese que se desaprovecha la luz y la ventilación debido a las rejas agregadas por inseguridad o por estar ubicada frente a vías rápidas de transporte.

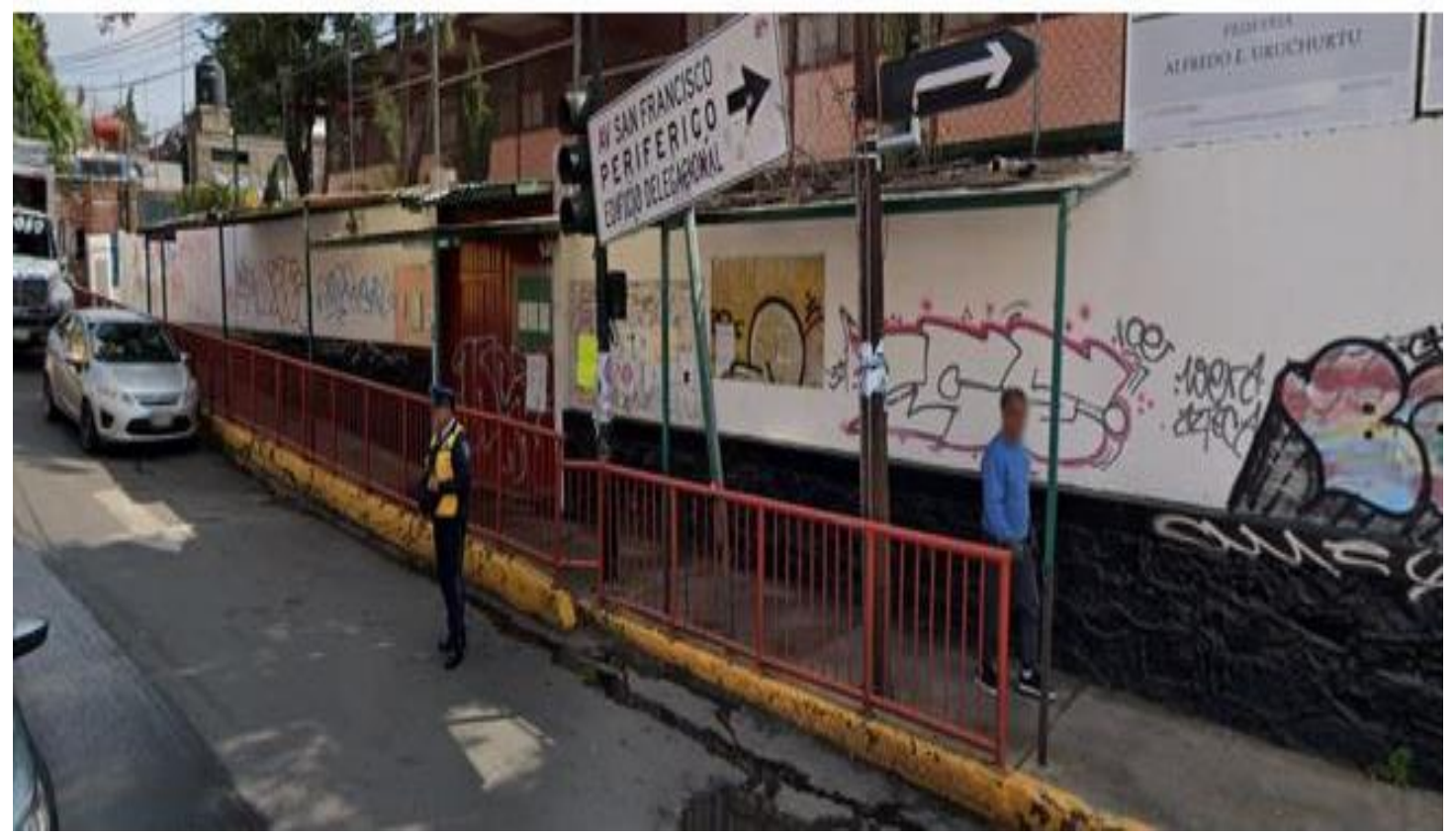

Fuente: Nancy Pacheco (2019) tomada con fines didácticos 


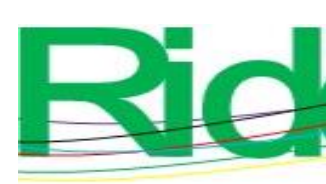

Revista Iberoamericana para la Investigación y el Desarrollo Educativo ISSN $2007-7467$

En la figura 7 se muestra el estado que guardan las INFE evaluadas referente a la variable edad del inmueble. Se observa que la mayoría de los edificios tienen más de medio siglo, lo que significa que fueron construidos para atender necesidades educativas de otras épocas. Otro punto destacable es que no existe evidencia de que las estructuras hayan sido planificadas como espacios educativos. Asimismo, se halló que ninguna institución cuenta con el mobiliario apropiado y que el mantenimiento es precario.

Figura 7. Evaluación de la INFE.

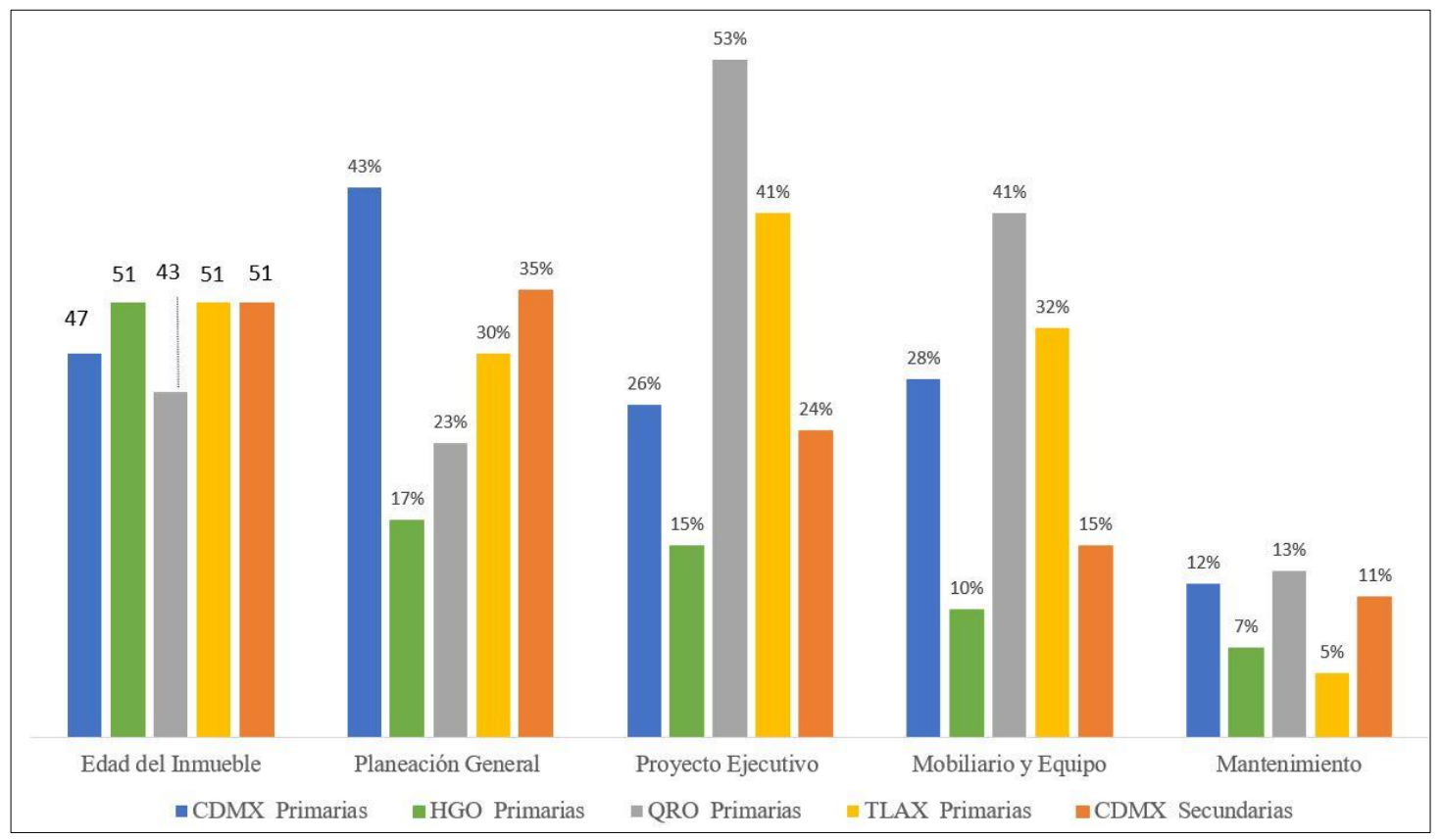

Fuente: Elaboración propia con fines didácticos

Con base en la información recabada en las tres fases del análisis, la figura 8 refleja las condiciones reales en que se encontraban los edificios educativos, es decir, escasos servicios municipales (55\% como máximo grado de desempeño normativo) y deficientes instalaciones eléctricas (48 \% como máximo en salones de clases, laboratorios y baños).

En cuanto a posibles amenazas del entorno para el edificio (en un radio menor de $10 \mathrm{~km}$ ), se encontraron las siguientes cifras: $35 \%$ vías rápidas, $23 \%$ paraderos de camiones (circulación excesiva de mercancía y personas), $12 \%$ zonas vandálicas (mercados y ambulantaje), $20 \%$ cerca de basureros clandestinos y $10 \%$ cerca de gasolineras.

Asimismo, fueron preocupantes los resultados obtenidos en cuanto a las condiciones hidrosanitarias. En este sentido, se puede señalar la falta de agua potable en los bebederos de los alumnos (los pocos edificios que los tenían), así como la carencia de muebles sanitarios para dotar a los baños. 


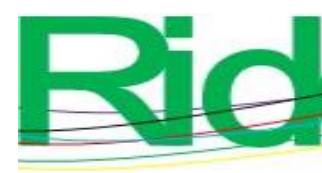

Revista Iberoamericana para la Investigación y el Desarrollo Educativo ISSN 2007 - 7467

Figura 8. Estado de la INFE.

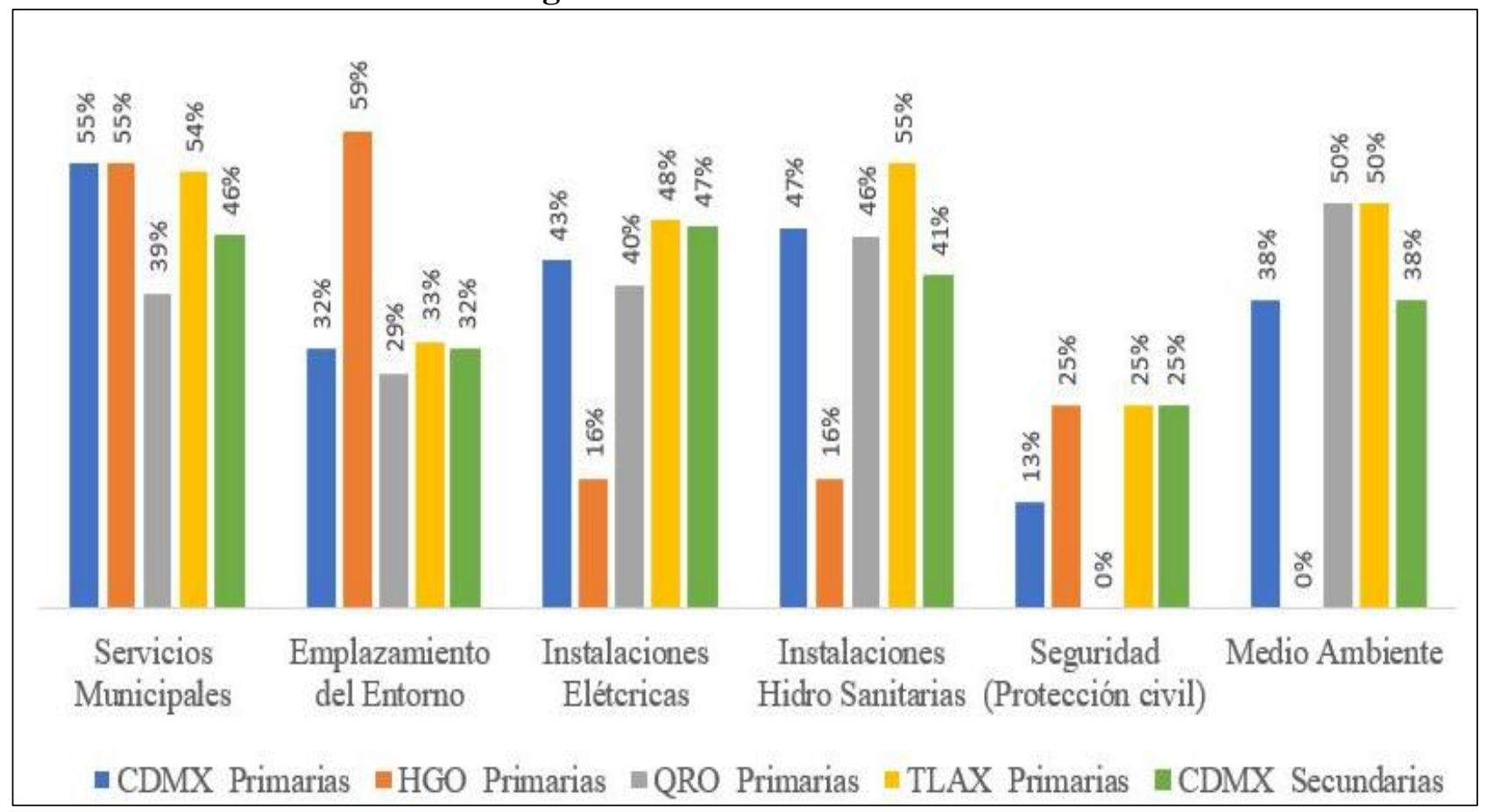

Fuente: Elaboración propia con fines didácticos

Con base en lo anterior, se pude subrayar de manera general que la INFE en la cual los alumnos reciben sus clases no cumple con la normativa establecida.

Ahora bien, y para dar continuidad al estudio realizado por Pacheco (2021) sobre la eficacia y eficiencia de la INFE en educación preescolar, en los siguientes párrafos se presenta una comparativa en los criterios señalados, aunque ahora incluyendo al nivel primario y secundario de la misma zona de estudio. A partir de este propósito, se formuló la siguiente interrogante: ¿el número de profesores disponibles es suficiente para brindar una educación de calidad a toda la población estudiantil? Para ello, se realizó el análisis de la muestra en comparación con el cumplimento de lo establecido por la SEP sobre el indicador alumno-maestro ver (tabla 2 y figura $9)$. 

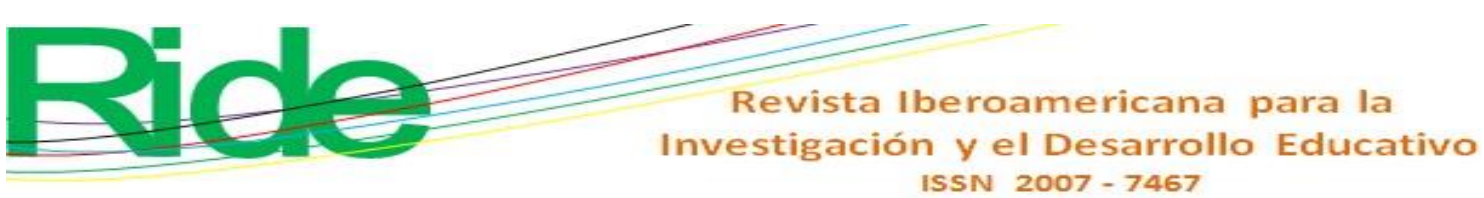

necesarias más horas de atención y dedicación al alumno, lo cual no se puede llevar a cabo por la carencia de docentes.

Figura 10. Primaria ubicada en la Ciudad de México, municipio de Magdalena Contreras. Se evidencia la demanda de alumnos, así como la carencia de docentes en los niveles básicos de educación.
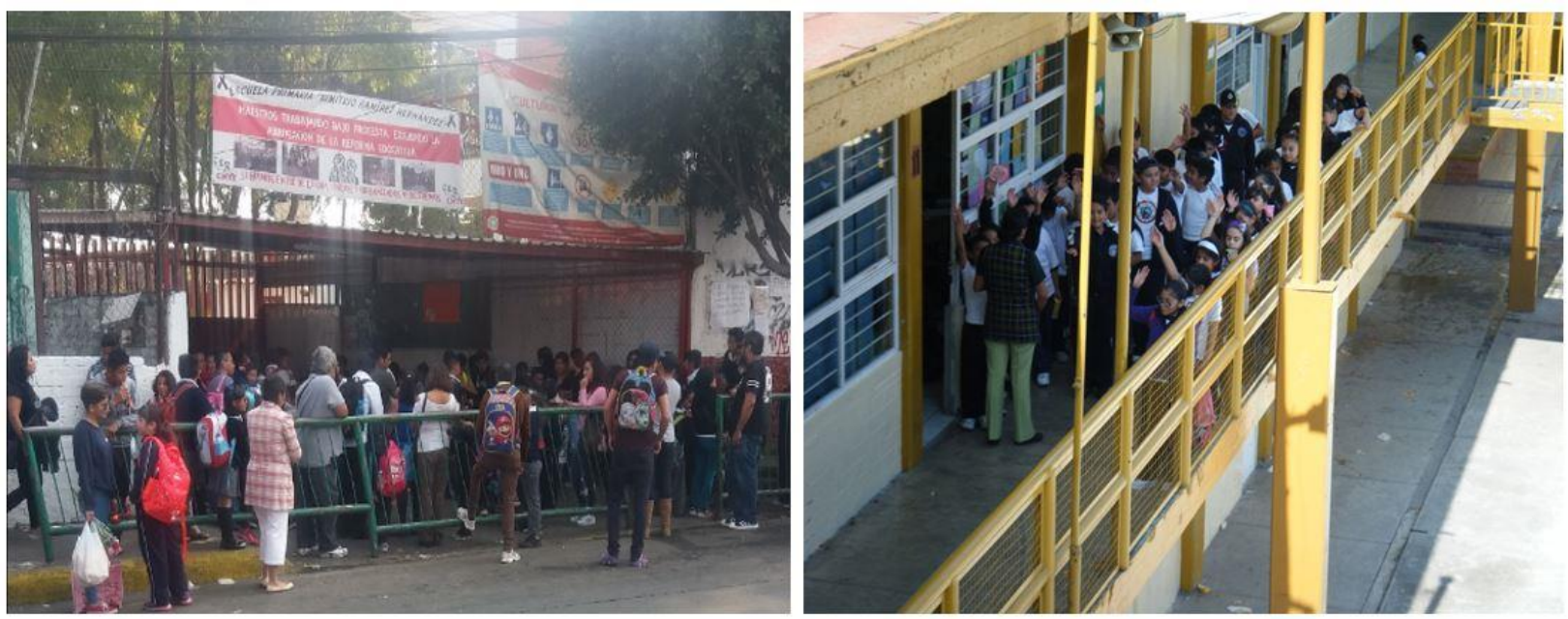

Fuente: Nancy Pacheco (2019) tomada con fines didácticos

Para contestar la interrogante ¿la infraestructura física de las escuelas es apta para la edad de sus usuarios?, se realizó el análisis con base en los requerimientos que señala la OCDE y en la información recopilada por la normativa aplicable ver (tabla 3 y figuras 11 y 12).

Tabla 3. Condiciones de la INFE de acuerdo con la edad del educando.

\begin{tabular}{|l|l|c|}
\hline \multicolumn{1}{|c|}{ Procedimiento aplicado a nivel preescolar } & \multicolumn{2}{|c|}{ Semejanzas } \\
\cline { 2 - 3 } & Primaria & Secundaria \\
\hline $\begin{array}{l}\text { Evaluación del cumplimiento normativo del } \\
\text { inmueble como espacio educativo, así como de la } \\
\text { observancia de los conceptos señalados por la la } \\
\text { OCDE. }\end{array}$ & $\begin{array}{l}\text { Se logró aplicar la metodología y } \\
\text { obtener el porcentaje de cumplimiento } \\
\text { para ambos niveles educativos. }\end{array}$ \\
\hline \multicolumn{2}{|c|}{ Discrepancias } \\
\hline $\begin{array}{l}\text { Las discrepancias se muestran en las figuras 11 y 12. En ellas se incluyó el nivel jardín de niños } \\
\text { para resaltar las diferencias encontradas en los niveles evaluados. Véase que la Ciudad de } \\
\text { México cumple con 73 \% en cuanto a uso específico para espacio educativo tanto a nivel jardín } \\
\text { de niños como a nivel secundaria, pero existen carencias de cumplimiento para el nivel de } \\
\text { primaria. Se destaca que ningún estado evaluado cumplió el mínimo necesario de los conceptos } \\
\text { solicitados por la OCDE. }\end{array}$ \\
\hline
\end{tabular}

Fuente: Elaboración propia con fines didácticos 


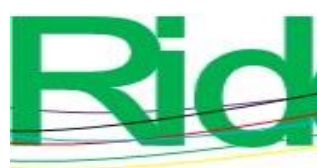

Revista Iberoamericana para la Investigación y el Desarrollo Educativo ISSN 2007 - 7467

Figura 11. Porcentaje de cumplimiento de los conceptos de la OCDE, así como de uso escolar.

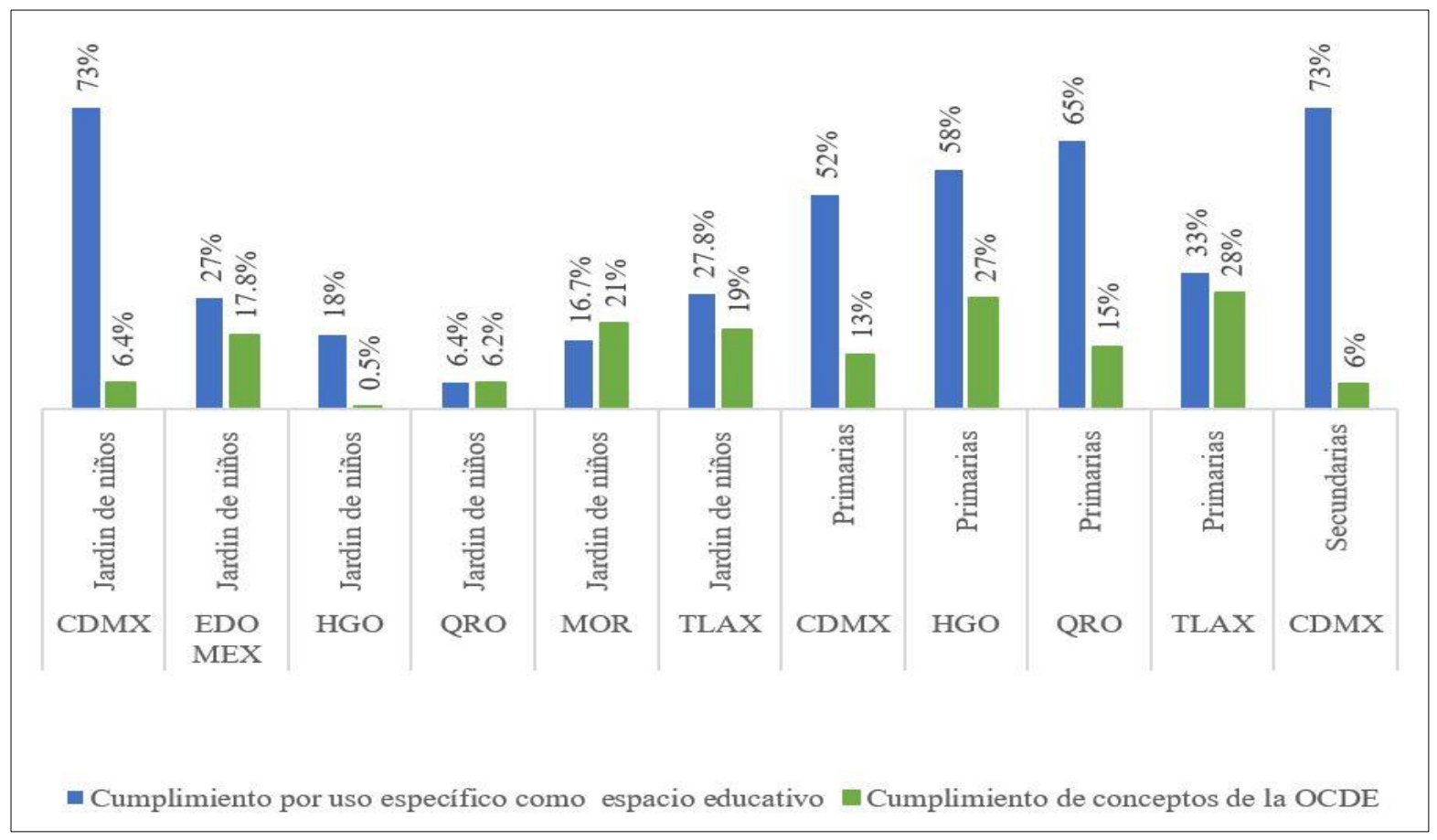

Fuente: Elaboración propia con fines didácticos

Figura 12. Resultado de las condiciones de los edificios de uso escolar.

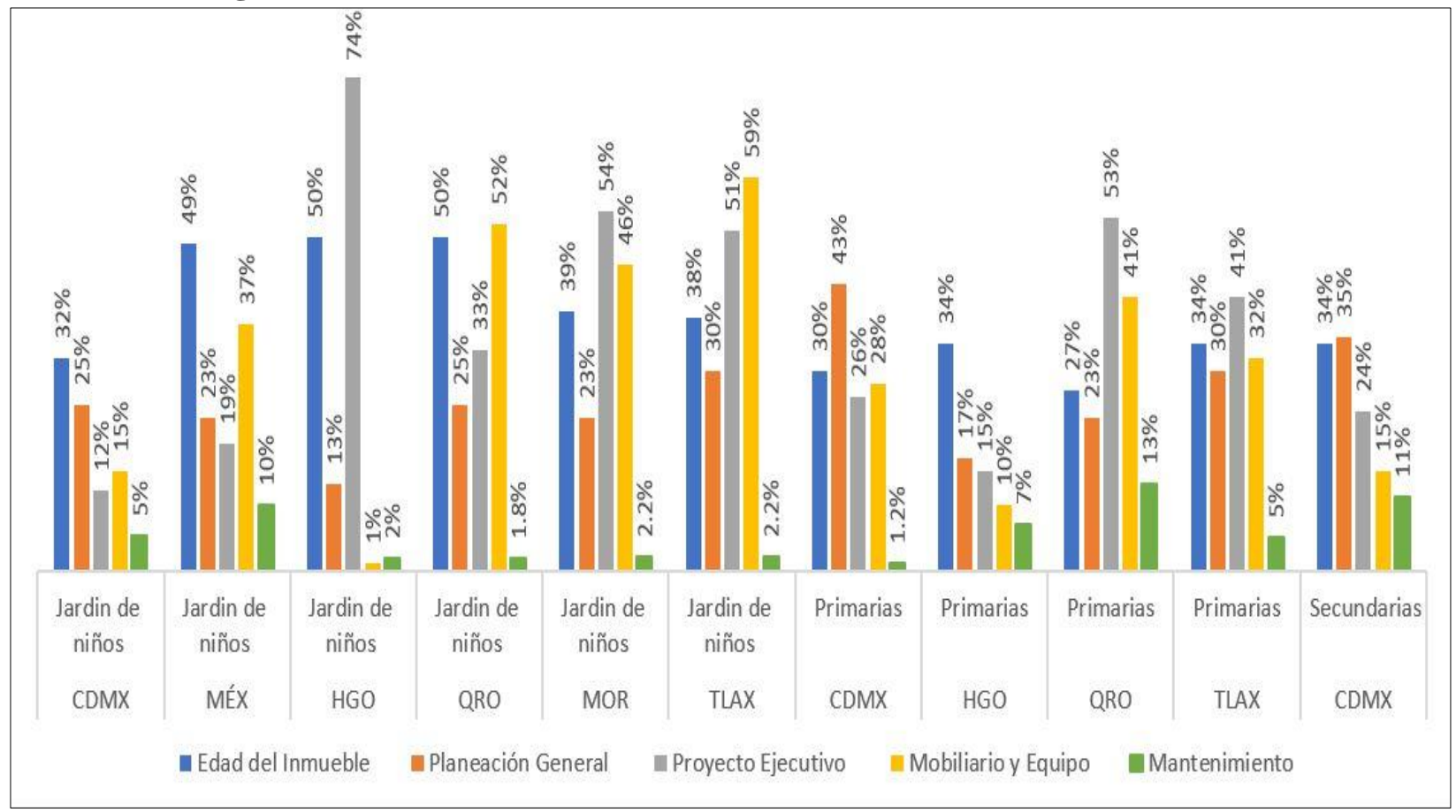

Fuente: Elaboración propia con fines didácticos 

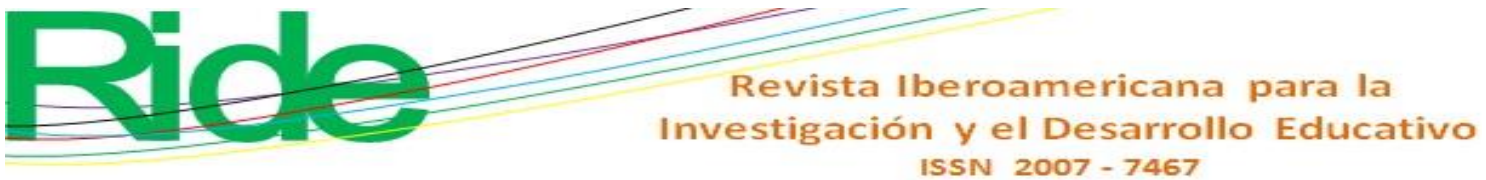

ISSN $2007-7467$

Los resultados demuestran que ninguno de los inmuebles examinados tuvo una planeación general, lo cual incide directamente en el aprendizaje de los alumnos. De forma general, el estado de Hidalgo presentó los mejores niveles en este rubro en el jardín de niños, seguido del estado de Querétaro y Tlaxcala (ambos a nivel de primaria). En cuanto al mobiliario básico, ningún plantel llegó a 60 \% de cumplimiento mínimo.

Figura 13. Estado actual del mobiliario de las escuelas evaluadas tanto a nivel primaria como secundaria en los estados de Hidalgo (c), Ciudad de México (d, e, f) y Tlaxcala (g, h).
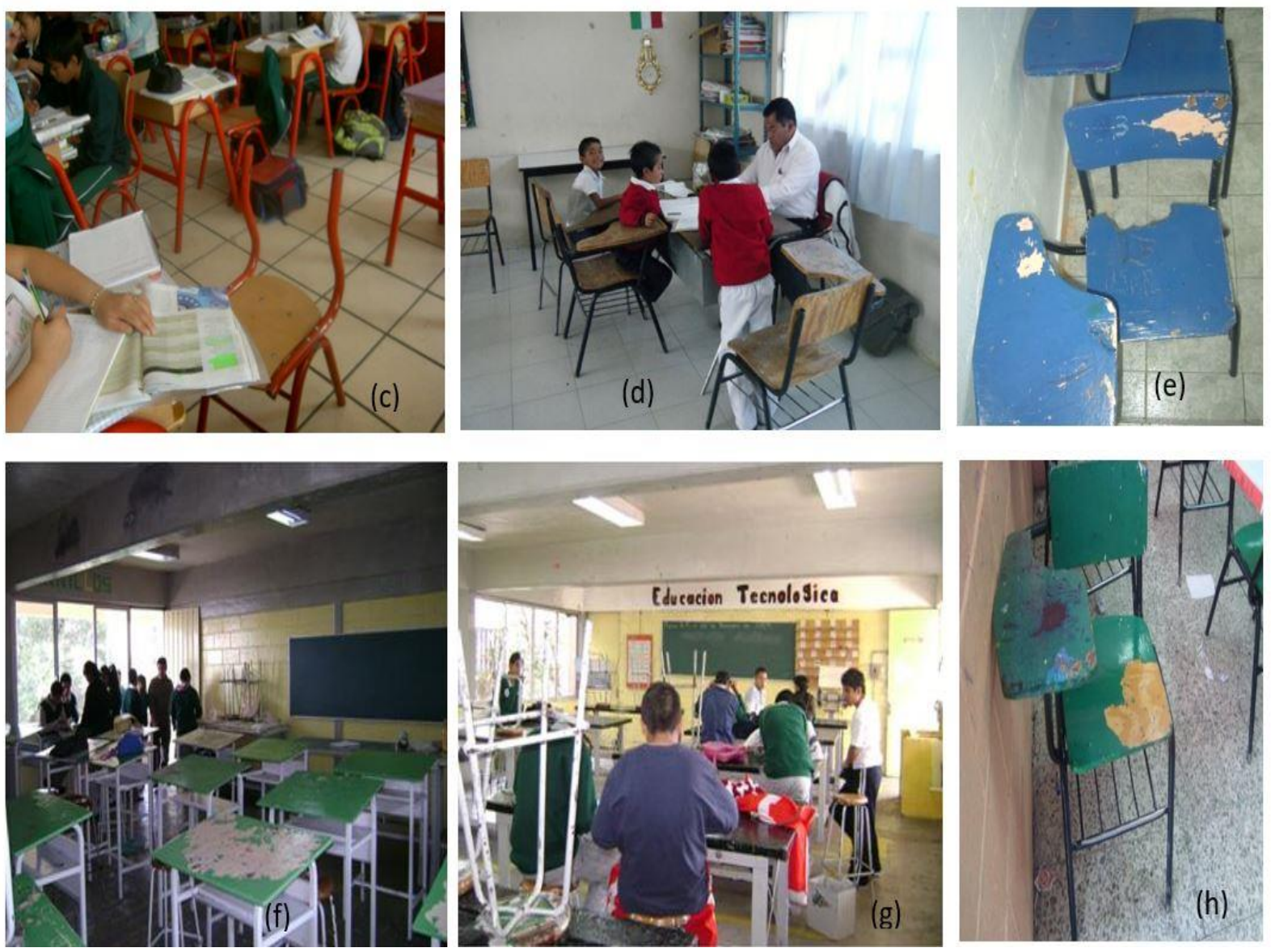

Fuente: Nancy Pacheco (2018) tomada con fines didácticos

La figura 13 mostró —en la imagen (c) — sillas sin respaldo que pueden ocasionar accidentes y que imposibilitan la realización de las actividades de manera adecuada; en la imagen (d) se aprecia que las sillas son más grandes que los alumnos - fuera de norma para el nivel y sin mantenimiento (e) y (h)—. Asimismo, sin luz en áreas básicas (como talleres) y sin equipo adecuado para los laboratorios $(\mathrm{g})$. 


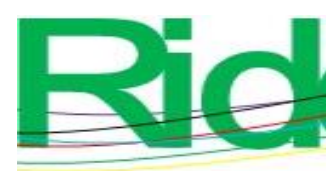

Revista Iberoamericana para la Investigación y el Desarrollo Educativo ISSN $2007-7467$

Para la pregunta ¿los espacios físicos usados para las actividades académicas cumplen con los requerimientos básicos para desarrollarlas con eficacia?, se presenta la comparativa de la tabla 4 y la figura 14.

Tabla 4. Estado real de la INFE

\begin{tabular}{|c|c|}
\hline \multirow{2}{*}{ Procedimiento aplicado a nivel preescolar } & Semejanzas \\
\hline & Secundaria \\
\hline $\begin{array}{l}\text { Metodología aplicada para comprobar el estado } \\
\text { real de la INFE evaluada. }\end{array}$ & $\begin{array}{l}\text { Se logró aplicar la metodología y } \\
\text { obtener el porcentaje de cumplimiento } \\
\text { para ambos niveles educativos. }\end{array}$ \\
\hline \multicolumn{2}{|c|}{ Discrepancias } \\
\hline \multicolumn{2}{|c|}{$\begin{array}{l}\text { Las diferencias se presentan en la figura 13, que quedaron sustentadas con la evidencia } \\
\text { fotográfica de las figuras } 13,15,16 \text {, y } 17 \text {, las cuales revelaron el impacto negativo en el } \\
\text { aprendizaje escolar de cerca de } 2524 \text { estudiantes de nivel preescolar, así como de } 1481 \text { tanto } \\
\text { de primaria como de secundaria. }\end{array}$} \\
\hline
\end{tabular}

Fuente: Elaboración propia con fines didácticos

Figura 14. Representación de la situación en las que se hallaron los planteles evaluados.

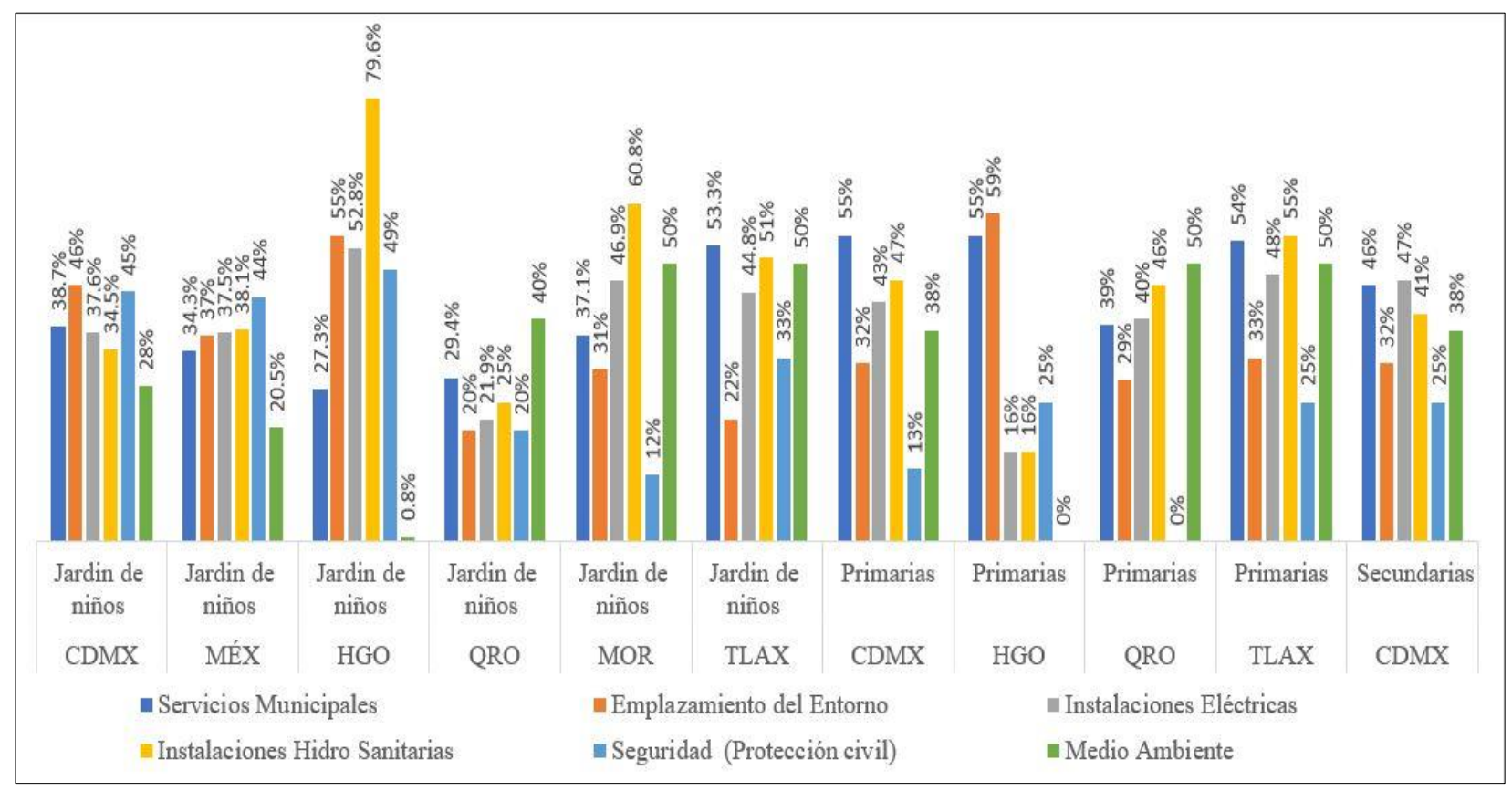

Fuente: Elaboración propia con fines didácticos 


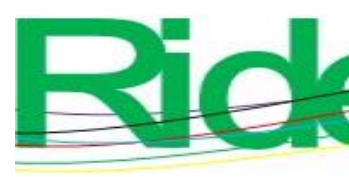

Revista Iberoamericana para la Investigación y el Desarrollo Educativo ISSN 2007 - 7467

De forma general, se puede indicar que los alumnos que asisten a educación básica enfrentan graves problemas no solo por las deficiencias de las instalaciones en sus escuelas, sino también debido a las carencias o incluso nula disponibilidad de los servicios básicos de infraestructura necesarios para la operación diaria. Se comprobó, además, que la cantidad de agua potable con la que se abastecen los planteles es insuficiente, aunado a que las cisternas no han recibido el mantenimiento mínimo indispensable. De hecho, los tinacos no cuentan con tapas, por lo que, en algunos casos, se llenan directamente de la llave general del inmueble, es decir, sin pasar por filtros. Todo esto afecta de forma negativa en el aprendizaje y genera ausentismo tanto de los alumnos como de los profesores.

Asimismo, en cuanto a instalaciones eléctricas, solo se cubre $48 \%$ a nivel de primaria en el estado de Tlaxcala y $47 \%$ en el nivel de secundaria de Ciudad de México. En síntesis, los salones no cuentan con energía eléctrica debido a fallas intermitentes en las zonas, falta del equipo adecuado, etc.

Por otra parte, en cuanto a las instalaciones sanitarias, se obtuvo $55 \%$ como valor máximo a nivel de primaria. Los principales problemas detectados en este criterio fueron la falta de conexión a la red municipal, el nulo mantenimiento de la red, la escasez o falta de muebles de baño, el carente mantenimiento de los bebederos, etc.

Referente al medio ambiente de las edificaciones, se hallaron áreas inseguras e insanas debido a factores como los siguientes: cercanía a gasolineras, mercados, hoteles, fabricas, líneas de alta tensión, terminales de autobuses, vialidades primarias con transito constante, etc. Por esto, resulta transcendental que los organismos encargados de la evaluación educativa atiendan estos problemas y orienten a las escuelas para que puedan ofrecer mejores espacios para la enseñanza.

En la figura 15 se evidencia que varios de los planteles educativos analizados son casas habitación con áreas adaptadas. Por ejemplo, en la imagen (i) se muestran las instalaciones eléctricas improvisadas por arriba de los pupitres de los alumnos; en la imagen (j) se observa el área adaptada sin ventilación y sin luz adecuadas para desempeñar actividades académicas; la imagen (k) demuestra que se ampliaron las áreas (salones) debido al exceso de la demanda escolar, aunque sin tener en cuenta el adecuado cumplimiento normativo; la imagen (1) refleja que se siguen impartiendo las clases aun cuando al mismo tiempo se están realizando las ampliaciones de las áreas; la imagen (m) enseña que muchas de las casas habitación están operando como escuela clausurando áreas de uso cotidiano, lo cual es incorrecto e inseguro para el desempeño de los educandos; en la imagen (n) se muestra cómo improvisan y adaptan el mobiliario para áreas de recreo; la imagen ( $\tilde{\mathrm{n}})$ muestra el techo improvisado, lo cual es inseguro y se encuentra fuera de la 


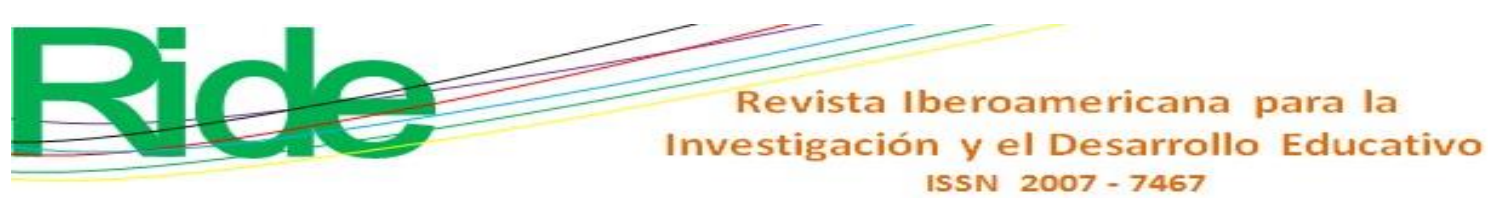

normativa; la imagen (o) evidencia el nulo mantenimiento; y la imagen (p) enseña la falta de iluminación en las áreas básicas donde se imparten las clases.

Figura 15. Condiciones de los espacios educativos para impartir clases tanto a nivel de educación primaria como secundaria. Imágenes (i), (l) y (m) de Hidalgo; imágenes (j), (ñ), (o) y (p) de la Ciudad de México; imágenes (k) y (n) de Tlaxcala.
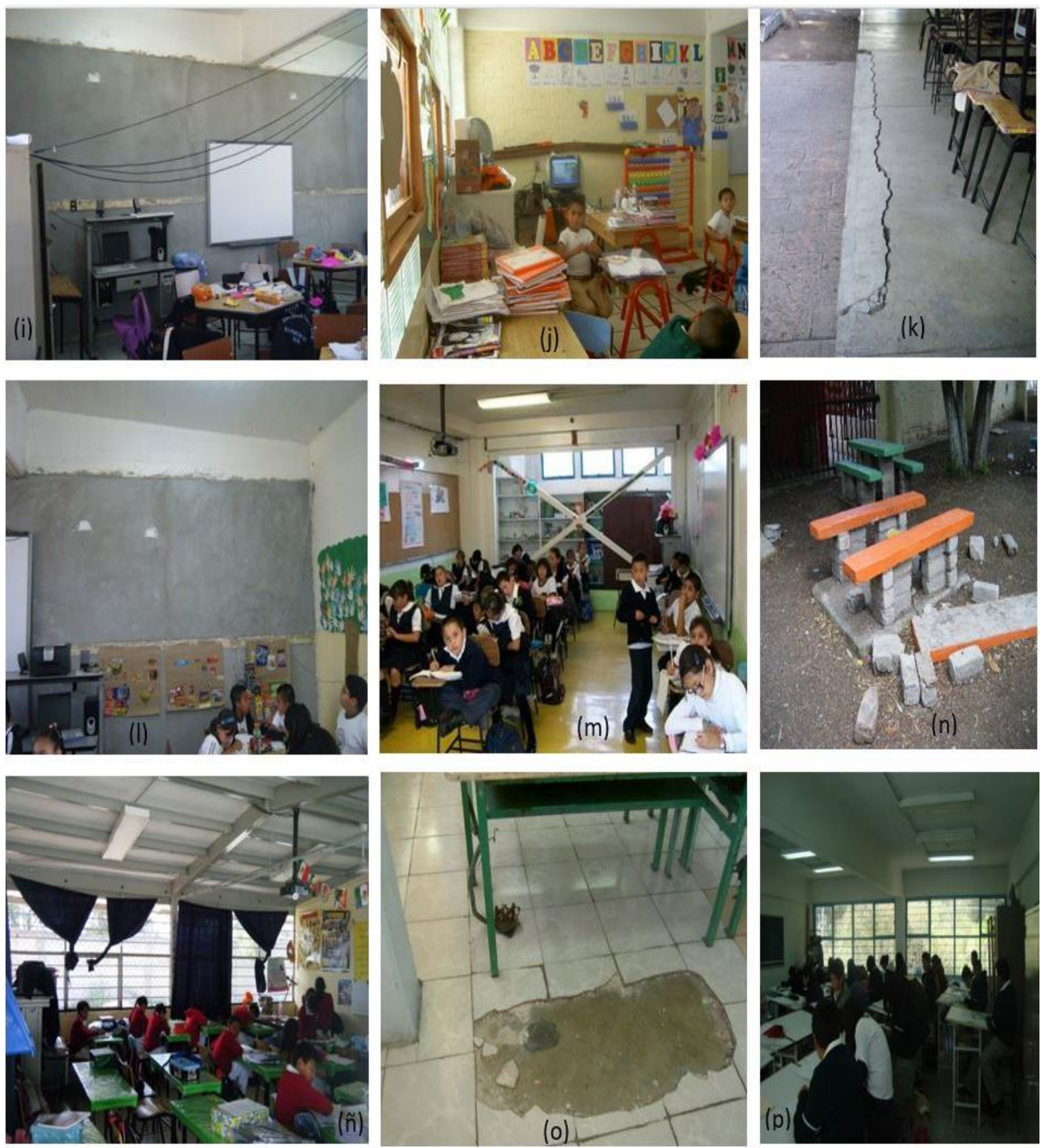

Fuente: Nancy Pacheco (2018) tomada con fines didácticos 

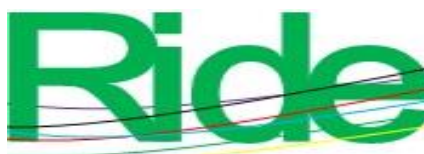

Revista Iberoamericana para la

Investigación y el Desarrollo Educativo

ISSN $2007-7467$

Figura 16. Evidencia del estado físico de las INFE evaluadas en los niveles primaria y secundaria. Imágenes (q), (t), (u) de Hidalgo; imágenes (r), (w), (x), (y) de la Ciudad de México, y (s), (v) de Tlaxcala.
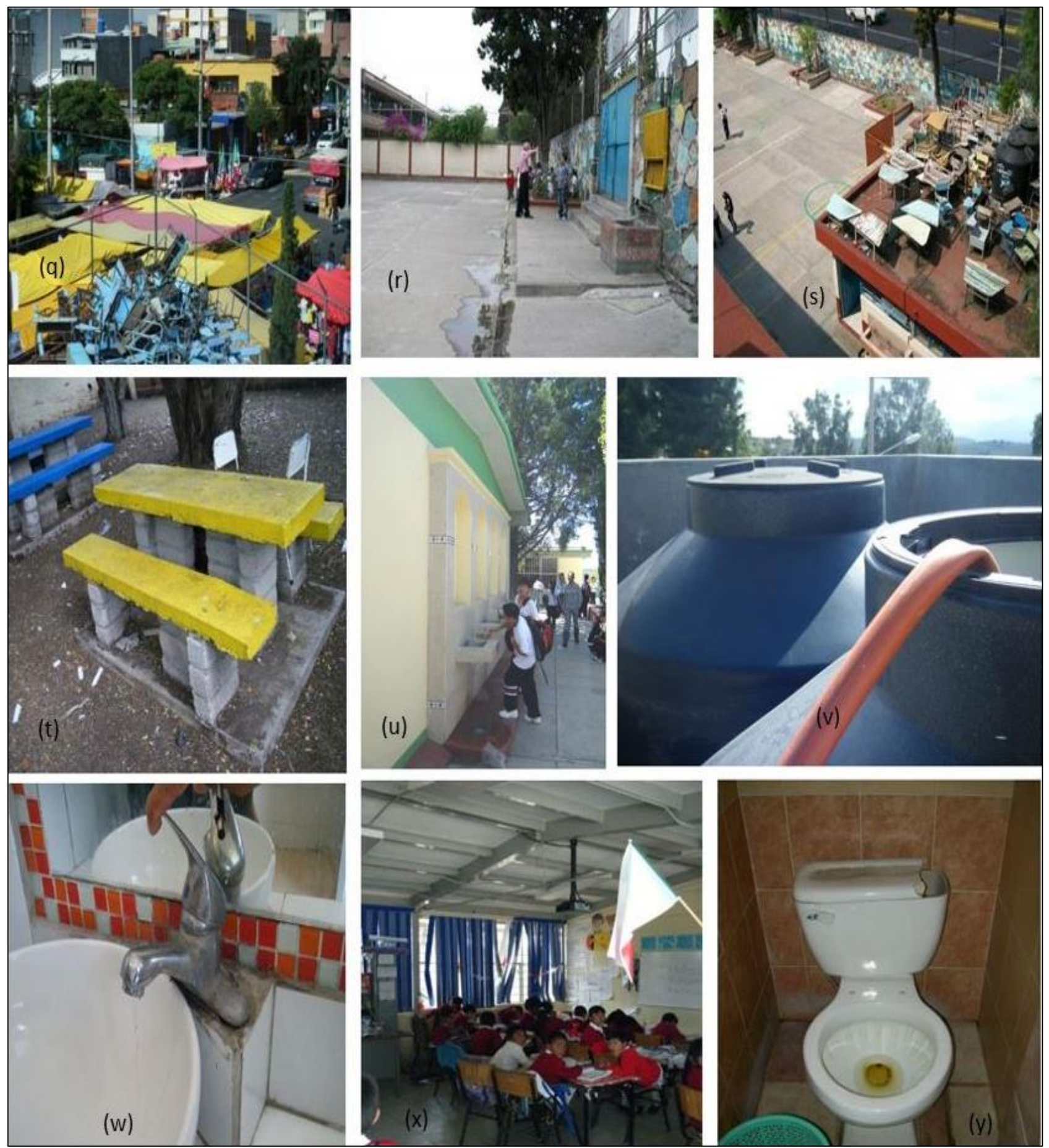

Fuente: Nancy Pacheco (2018) tomada con fines didácticos 


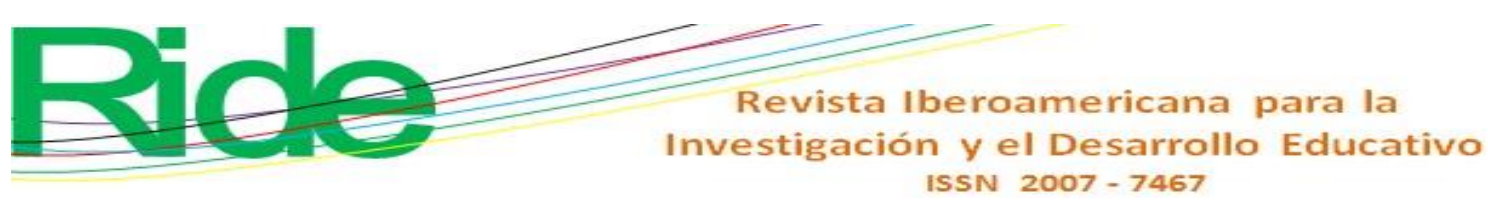

Figura 17. Instalaciones hidrosanitarias en mal estado y ambiente carente de higiene tanto en educación primaria como en secundaria. Imágenes (a1), (d1), (e1), (g1) de Hidalgo; imágenes (b1), (h1), (11) de la Ciudad de México; e imágenes (c1), (f1), (i1), (j1), (k1) de Tlaxcala.
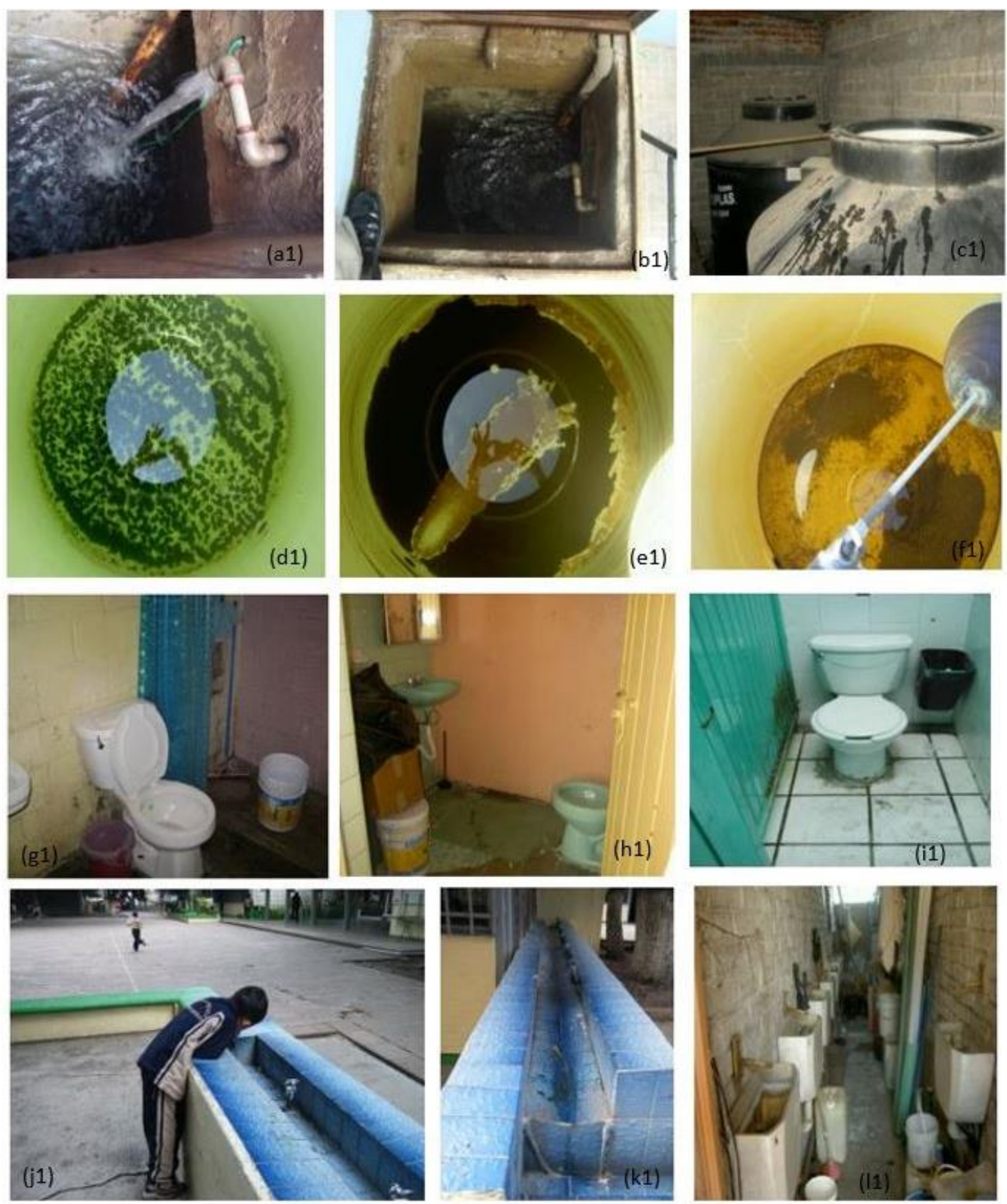

Fuente: Nancy Pacheco (2018) tomada con fines didácticos 


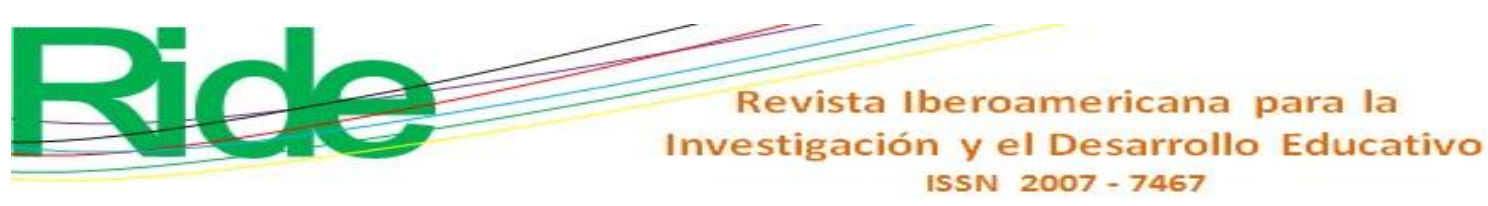

Figura 18. Carencia total del mantenimiento eléctrico en las instalaciones tanto en educación primaria como en secundaria. Imágenes (m1), (o1), (p1) de Hidalgo, imágenes (n1), (r1), (s1),

(t1) de la Ciudad de México, e imágenes (ñ1), (q1) de Tlaxcala.
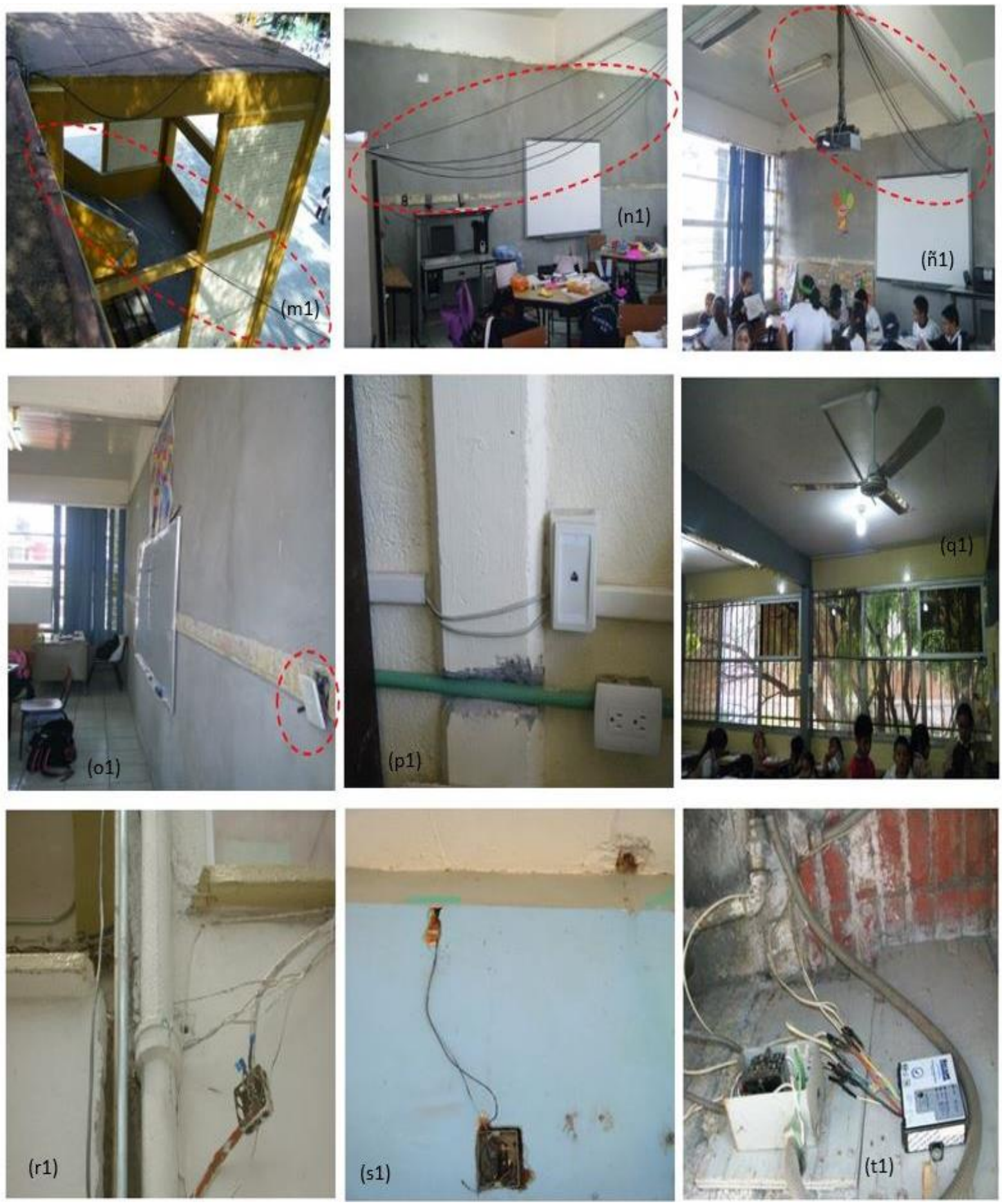

Fuente: Nancy Pacheco (2018) tomada con fines didácticos

Finalmente, se presentan los resultados recabados con la siguiente interrogante: ¿los planteles educativos cuentan con las condiciones de infraestructura adecuadas para operar de manera segura en medio de la actual situación generada por la pandemia de covid-19? Al respecto, 


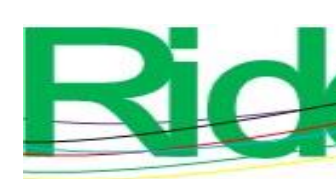

e

Revista Iberoamericana para la

Investigación y el Desarrollo Educativo

ISSN 2007 - 7467

se puede indicar (como se evidenció en las figuras 13, 15, 16 y 17) que las instituciones no cuentan con las áreas mínimas requeridas para atender a toda la población estudiantil. De hecho, como se demostró antes, ha quedado en evidencia que los docentes deben trabajar con un número elevado de estudiantes. Asimismo, respecto a la de iluminación por áreas (luxes) y a la ventilación requerida por aula, se puede asegurar que es nulo el cumplimiento normativo (tablas 5 y Figura 19).

Tabla 5. Estado real de iluminación de aulas.

\begin{tabular}{|c|c|c|c|c|c|c|}
\hline \multicolumn{3}{|c|}{$\begin{array}{l}\text { Niveles mínimos por cumplir de } \\
\text { acuerdo a la normatividad }\end{array}$} & \multicolumn{4}{|c|}{$\begin{array}{l}\text { Cumplimiento de niveles de luxes obtenidos de las } \\
\qquad \text { INFE evaluadas }\end{array}$} \\
\hline $\begin{array}{c}\text { Tipo de } \\
\text { edificación }\end{array}$ & \multirow[b]{2}{*}{ Local } & \multirow[b]{2}{*}{$\begin{array}{c}\text { Nivel } \\
\text { de } \\
\text { luxes }\end{array}$} & \multicolumn{2}{|c|}{ Primaria } & \multicolumn{2}{|c|}{ Secundaria } \\
\hline $\begin{array}{l}\text { Edificación } \\
\text { escolar e } \\
\text { instituciones } \\
\text { científicas }\end{array}$ & & & Local & $\begin{array}{c}\text { Nivel } \\
\text { de } \\
\text { luxes }\end{array}$ & Local & $\begin{array}{l}\text { Nivel de } \\
\text { luxes }\end{array}$ \\
\hline $\begin{array}{l}\text { Atención a } \\
\text { educación } \\
\text { preescolar }\end{array}$ & Aulas & 250 & Aulas & 200 & Aulas & 219 \\
\hline \multirow{2}{*}{$\begin{array}{c}\text { Educación } \\
\text { formal básica } \\
\text { y media }\end{array}$} & $\begin{array}{c}\text { Aulas y } \\
\text { laboratorios }\end{array}$ & 300 & $\begin{array}{c}\text { Aulas y } \\
\text { laboratorios }\end{array}$ & 254 & $\begin{array}{c}\text { Aulas y } \\
\text { laboratorios }\end{array}$ & 260 \\
\hline & $\begin{array}{l}\text { Circulacion } \\
\text { es }\end{array}$ & 100 & $\begin{array}{l}\text { Circulacion } \\
\text { es }\end{array}$ & 76 & $\begin{array}{l}\text { circulacione } \\
\qquad \mathrm{s}\end{array}$ & 80 \\
\hline $\begin{array}{l}\text { Ver detalle } \\
\text { "Instalaciones } \\
\text { sistemas de a } \\
\text { energética en }\end{array}$ & $\begin{array}{l}\text { n las sigui } \\
\text { eléctricas (ut }\end{array}$ & $\begin{array}{l}\text { tes No } \\
\text { zación) } \\
\text { ificios }\end{array}$ & $\begin{array}{l}\text { as Oficiale } \\
\text { NOM-007-E } \\
\text { residenciale }\end{array}$ & ;OI & $\begin{array}{l}\text { has: NOM-00 } \\
\text { "Eficiencia } \\
\text { 013-ENER-20 }\end{array}$ & $\begin{array}{l}\text { SEDE-2018 } \\
\text { rgética parc } \\
\text { "Eficiencia } \\
\text {; NOM-025 }\end{array}$ \\
\hline
\end{tabular}

Fuente: Elaboración propia con fines didácticos 


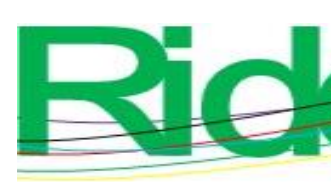

Revista Iberoamericana para la Investigación y el Desarrollo Educativo ISSN $2007-7467$

Figura 19. Estado real de ventilación en las aulas.

\begin{tabular}{|c|c|c|c|c|c|}
\hline \multicolumn{6}{|c|}{ Volúmenes mínimos de aire } \\
\hline \multicolumn{2}{|c|}{$\begin{array}{l}\text { Niveles mínimos por cumplir } \\
\text { de acuerdo a la normatividad }\end{array}$} & \multicolumn{4}{|c|}{$\begin{array}{l}\text { Cumplimiento de volúmenes mínimos de aire por aulas } \\
\text { obtenidos de las INFE evaluadas }\end{array}$} \\
\hline \multirow{2}{*}{$\begin{array}{l}\text { Volúmenes } \\
\text { disponibles } \\
\text { por alumno } \\
\qquad\left(\mathrm{m}^{3}\right)\end{array}$} & \multirow{2}{*}{$\begin{array}{l}\text { Número de } \\
\text { renovaciones } \\
\text { por alumno y } \\
\text { por hora }\end{array}$} & & aria & Secu & ndaria \\
\hline & & $\begin{array}{l}\text { Volúmenes } \\
\text { disponibles } \\
\text { por alumno } \\
\qquad\left(\mathrm{m}^{3}\right)\end{array}$ & $\begin{array}{l}\text { Número de } \\
\text { renovaciones } \\
\text { por alumno y } \\
\text { por hora }\end{array}$ & $\begin{array}{l}\text { Volúmenes } \\
\text { disponibles } \\
\text { por alumno } \\
\qquad\left(\mathrm{m}^{3}\right)\end{array}$ & $\begin{array}{c}\text { Número de } \\
\text { renovaciones } \\
\text { por alumno y } \\
\text { por hora }\end{array}$ \\
\hline 3 & 9 & 2 & 7 & 2 & 6 \\
\hline 5 & 5 & 3 & 3 & 2 & 4 \\
\hline 7 & 4 & 5 & 3 & 5 & 3 \\
\hline 9 & 3 & 6 & 2 & 7 & 2 \\
\hline \multicolumn{6}{|c|}{$\begin{array}{l}\text { La renovación del aire se podrá realizar de forma natural a través de los espacios abiertos en } \\
\text { ventanas y/o de forma mecánica por medio de aparatos y accesorios destinados para tal fin. } \\
\text { Dependiendo de la localización geográfica, se recomienda proporcionar una ventilación natural } \\
\text { cruzada controlada, de por lo menos un tercio }(1 / 3) \text { del área de la ventana o un noveno (1/9) del } \\
\text { área local. El porcentaje mínimo de ventilación será de } 5 \% \text { del área del local. }\end{array}$} \\
\hline
\end{tabular}

Fuente: Elaboración propia con fines didácticos

Referente al mobiliario y a los equipos, así como a las instalaciones hidráulicas e hidrosanitarias, en las figuras 13, 15, 16 y 17 se precia el grado de incumpliendo. Lo anterior nos demuestra que si se siguiera la normatividad básica de la INFE para atender esta situación actual generada por la covid-19, se podría cumplir con algunas medias básicas emitidas por la Organización Mundial de la Salud, como son una adecuada distancia (incumplimiento por exceso de demanda poblacional), medidas de higiene de manos y personal (incumplimiento por escasez de agua y número insuficiente de baños, lavabos y bebederos), protección y seguridad (grado de cumplimento máximo de $25 \%$ obtenido), ventilación e iluminación adecuadas (incumplimiento por estar ubicadas en zonas de alta inseguridad, colindancia con basureros, paraderos y ambulantaje). Todo esto, como ya se ha mencionado, ha repercutido y seguirá influyendo de forma negativa en el aprendizaje de los escolares de todos los niveles educativos. 


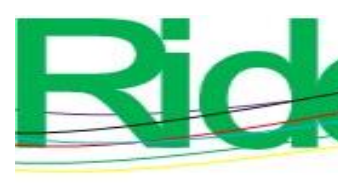

Revista Iberoamericana para la Investigación y el Desarrollo Educativo ISSN 2007-7467

\section{Discusión}

Según se aprecia en el volumen y en la fecha de la literatura relacionada con la infraestructura educativa, se puede decir que ha surgido un interés en los aspectos específicos del diseño de la INFE, ya que se ha percibido que esta variable afecta la práctica docente y el aprendizaje de los estudiantes. Esta afirmación, de hecho, se puede organizar en una serie de temas clave que se describen a continuación.

En cuanto a los impactos ambientales, Temple (2007) y Higgins et al. (2005) se refieren a fuentes que describen las formas en que las condiciones ambientales específicas impactan en el aprendizaje de los estudiantes, es decir, el ruido, la temperatura, la calidad del aire, la ventilación y la iluminación (Earthman y Brown, 2004; Higgins et al., 2005; Keep, 2002; Lackney y Jacobs, 2004). Aunado a esto, se debe indicar que existe mucho debate sobre la importancia de elementos específicos como el color, la estética y las propiedades ergonómicas de los muebles, ya que el aumento en la comodidad de los maestros y estudiantes eleva los niveles de concentración y desenvolvimiento en las tareas desarrolladas (Bateman, 2009).

En concordancia con esta idea, Bullard (2010) y Simont et al. (2007) explican que en diversas investigaciones se vincula la calidad de los edificios escolares con el desarrollo infantil a nivel educativo. Este aspecto se puede dividir en dos supuestos:

1. Se asigna a la INFE un rol estimulante: es decir, se sostiene que un ambiente más agradable tiende a generar sensaciones de bienestar que predeterminan tanto a los discípulos como a los educadores para que tengan una mejor actitud frente a la enseñanza y el aprendizaje.

2. Se le atribuye al estado de la INFE su uso dado que opera directamente facilitando el proceso enseñanza-aprendizaje (Young, 2003, citado por Campana et al., 2014).

Asimismo, Ponce de León y Alarcón (2014) señalan que el ruido afecta el desarrollo psicológico de los estudiantes, lo que intuye negativamente en el proceso de aprendizaje; mientras que Coronel (2017) indica que la INFE tiene un papel esencial en la estimulación de los estudiantes.

Respecto al nivel funcional, estudios como los de Martínez et al. (2013), Muñoz y Guzmán (2010), Campana et al. (2014), Duarte et al. $(2011,2017)$ y Del Valle (2001) establecen que la INFE impacta en los resultados de exámenes estandarizados de los estudiantes.

En cuanto a la influencia indirecta a nivel motivacional, los trabajos de Blackmore et al. (2011) y Del Valle (2001) muestran que la infraestructura repercute en el aprendizaje al incentivar el involucramiento, así como el trabajo colaborativo docente. 


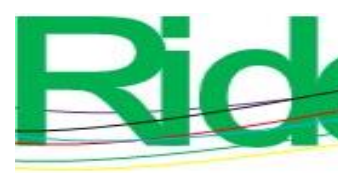

Revista Iberoamericana para la Investigación y el Desarrollo Educativo ISSN $2007-7467$

En síntesis, los diferentes estudios sobre la INFE han mostrado que es un elemento fundamental, y al mismo tiempo complejo, para el aprendizaje de las niñas, niños y adolescentes, de ahí que se deba profundizar en ello. En tal sentido, la presente investigación tiene una gran relevancia, ya que en ninguna otra se han abordado tantas variables (p. ej., servicios públicos, instalaciones, áreas básicas, iluminación, ventilación, relación alumno/docente, etc.), las cuales fueron analizadas según la normatividad vigente sobre los edificios educativos, y su impacto en la situación actual de salud generada por la covid-19.

\section{Conclusiones}

A partir de los resultados recabados en esta investigación, es posible detectar con mayor certeza los aspectos que deben tomarse en consideración para el mejor funcionamiento de las escuelas y para una correcta inversión de los recursos destinados para tal fin, lo cual, además, puede servir para la prevención de accidentes, afectaciones y deserción de los alumnos. Al respecto, cabe señalar que, en este estudio, de manera general, se recabó evidencia que demuestra que es habitual la fabricación de espacios educativos improvisados (p. ej., salones hechos con láminas metálicas acanaladas o de multipanel).

Este tipo de deficiencias son más significativas en la actualidad debido a la pandemia que se vive en todo el mundo, ya que para volver a clases presenciales resulta fundamental que los planteles cumplan con ciertos requisitos mínimos; por ejemplo, ventilación mínima requerida, iluminación adecuada, dimensiones optimas de las aulas para albergar a grupos numerosos de alumnos, suministro de agua potable para lavados de manos y desinfección de los espacios, etc. En pocas palabras, la infraestructura física educativa debe estar en condiciones de cumplir con lo que se estipula en la Constitución Política de los Estados Unidos de México y en la Ley General de Educación, donde se establece que el Estado deberá garantizar la educación obligatoria y de calidad.

Finalmente, como futuras líneas de investigación es importante que este tipo de análisis se aplique en otros niveles educativos para enriquecer los datos recabados. Es decir, se puede incluir a poblaciones de otros estados del país y a instituciones de educación media superior y superior de centros públicos y privados. 


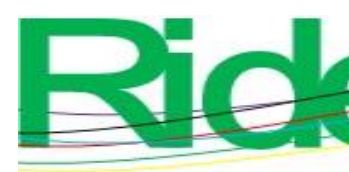

Revista Iberoamericana para la Investigación y el Desarrollo Educativo ISSN $2007-7467$

\section{Referencias}

Bateman, D. (2009). Playing with Reggio spaces in higher education for teacher education. Australian Association for Research in Education International Education Research Conference, Australian Association for Reseach in Education.

Blackmore, J., Bateman, D., Loughlin, J, O’Mara, J. and Aranda, G. (2011). Research into the Connection between Built Learning Spaces and Student Outcomes, Melbourne. Education Policy and Research Division Department of Education and Early Childhood Development. Retrieved from https://pdfs.semanticscholar.org/e7a3/8d0bc171b32b3dd966dee7344f274d02cdce.pdf

Blanco, E. (2009). Eficacia escolar y desigualdad: aportes para la política educativa. Perfiles Latinoamericanos, 17(34), 51-85.

Bullard, J. (2010). Creating environments for learning: Birth to age eight. Pearson Education Inc., Upper Saddle River, NJ.

Campana, Y., Velasco, D. y Guerrero, E. (2014). Inversión en infraestructura educativa: una aproximación a la medición de sus impactos a partir de la experiencia de los colegios emblemáticos. Lima. Informe final del proyecto mediano presentado en el marco del Concurso de Investigación 2013 XV, CIES/IDRC/Fundación M. J. Bustamante.

Cheryan, S., Ziegler, S., Plaut, V. and Meltzoff, A. (2014). Designing Class- rooms to Maximize Student Achivement. Policy Insights from the Behavioral and Brain Sciences, 1(1), 4-12.

Coronel, E. (2017). Impacto del Programa Nacional de Infraestructura Educativa en el rendimiento escolar de los estudiantes de las instituciones educativas de nivel primario del distrito de Pimentel 2010 al 2015 (tesis de maestría). Trujillo, Perú: Universidad César Vallejo.

Del Valle, Á. (2001). Rendimiento escolar: infraestructura y medios de enseñanzaaprendizaje. Revista Educación, 10(19), 33-56.

Diario Oficial de la Federación [DOF] (18 de junio de 2014). Procedimiento para la Evaluación de la Conformidad de la Norma Oficial Mexicana NOM-001-SEDE-2012, Instalaciones eléctricas (utilización). México. D. F. Recuperado de http://consultaema.mx:75/pqtinformativo/GENERAL/UV/Documentos_por_area/Eficien cia\%20Energetica\%20e\%20Instalaciones_Electricas/6\%20PEC-NOM-001-SEDE-2012JUN-14.pdf 


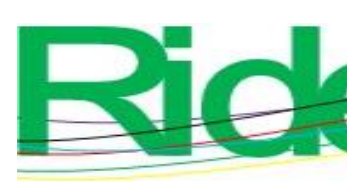

Revista Iberoamericana para la

Investigación y el Desarrollo Educativo

ISSN $2007-7467$

Diario Oficial de la Federación [DOF] (30 de septiembre de 2019). Ley General de Educación [LGE]. México. D.F. Recuperado de https://dof.gob.mx/nota_detalle.php?codigo=5573858\&fecha=30/09/2019

Diario Oficial de la Federación [DOF] (4 de abril de 2019). Acuerdo por el que se emiten los lineamientos específicos de operación del Programa Nacional de Reconstrucción en el sector educativo para el ejercicio fiscal 2019. México. D. F. Recuperado de http://www.reconstruyendoesperanza.gob.mx/difusion/wpcontent/uploads/2019/09/Lineamientos-Especificos_INIFED-2019.pdf

Duarte, J., Jaureguiberry, F. y Racimo, M. (2017). Suficiencia, equidad y efectividad de la infraestructura escolar en América Latina según el TERCE. Santiago de Chile: UNESCO.

Duarte, J., Moreno, M. y Gargiulo, C. (2011). Infraestructura y aprendizaje en la educación básica latinoamericana: un análisis a partir del SERCE. Washington, DC, BID.

Earthman, G. and Brown, M. (2009). Teacher attitudes about classroom conditions. Journal of Educational Administration, 47(3), 323-335.

Gaceta Oficial de la Ciudad de México (15 de diciembre de 2017). Órgano de Difusión del Gobierno de la Ciudad de México. Normas Técnicas del Reglamento de Construcciones México. D. F. Recuperado de https://www.smig.org.mx/archivos/NTC2017/normastecnicas-complementarias-reglamento-construcciones-cdmx-2017.pdf

Gaceta Oficial del Distrito Federal (2 de enero de 2004). Administración Pública del Distrito Federal Jefatura de Gobierno Reglamento de Construcciones para el Distrito Federal. México. D. F. Recuperado de http://cgservicios.df.gob.mx/prontuario/vigente/r38501.pdf Higgins, S., Hall, E., Wall, K., Woolner, P. and McCaughey, C. (2005). The impact of school environments: A literature review. The Centre for Learning and Teaching, University of Newcastle. Retrieved from http://www.stakeholderdesign.com/designcouncilreport.pdf Instituto de la Infraestructura Física Educativa [INIFED] (2014). Normas y especificaciones para estudios, proyectos, construcción e instalaciones. Instituto de la Infraestructura Física Educativa. Recuperado de https://www.gob.mx/cms/uploads/attachment/file/89279/Tomo2_Accesibilidad.pdf Instituto de la Infraestructura Física Educativa [INIFED] (2019). Anexo 1. Formato de información técnica para la evaluación para la certificación de la calidad de la INFE 2019. Instituto de la Infraestructura Física $\quad$ Educativa. Recuperado de https://www.gob.mx/inifed/documentos/anexo-1-formato-de-informacion-tecnica-para-laevaluacion-para-la-certificacion-de-la-calidad-de-la-infe-2019 

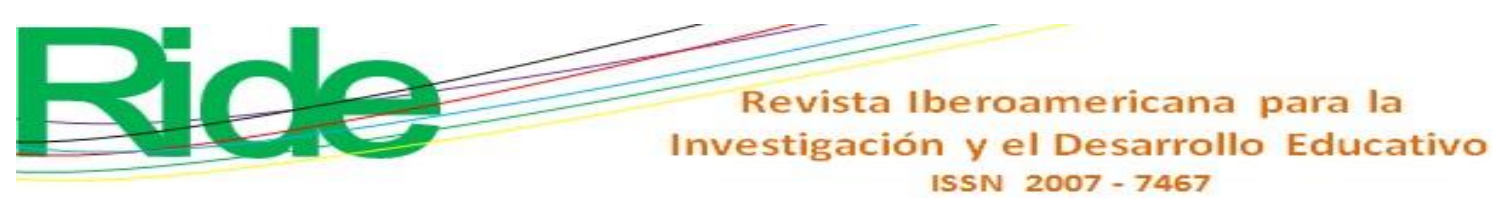

Keep, G. (2002) Buildings that teach. The Educational Facilities Planner, 37(2). Retrieved from https://eric.ed.gov/?id=EJ653839

Lackney, J. A. and Jacobs, P. J. (2002). Teachers as placemakers: Investigating teachers' use of the physical learning environment in instructional design. Research Report. Retrieved from http://www.eric.ed.gov/PDFS/ED463645.pdf

Martínez Cervantes, T., Soto, E., Mendivil, P., Salazar Silva y Velasco Arellanes, F. (2013). Efectos de la infraestructura básica en los resultados de la prueba ENLACE de la educación media superior tecnológico mexicana. REICE. Revista Iberoamericana sobre Calidad, Eficacia y Cambio en Educación, 11(4), 93-107.

Muñoz, C. y Guzmán, J. (2010). Una exploración de los factores determinantes del rendimiento escolar en la educación primaria. Revista Latinoamericana de Estudios Educativos, 40(2), 167-191.

Murillo, F. (coord.) (2003). La investigación sobre eficacia escolar en Iberoamérica. Revisión Internacional del estado de la cuestión. Bogotá: Convenio Andrés Bello.

Murillo, J. and Román, M. (2011). School Infrastructure and Resources do Matter: Analysis of the incidence of school resources on the performance of Latin American students. International Journal of Research, Policy and Practice, 22(1), 29-50.

Norma Mexicana (2013). NMX-R-021-SCFI-2013 Escuelas —calidad de la infraestructura física educativarequisitos. Recuperado de https://www.gob.mx/cms/uploads/attachment/file/104914/NMX-R021_Calidad_de_la_INFE_requisitos.pdf

Norma Mexicana (2015a). NMX-R-084-SCFI-2015 Escuelas —levantamiento de datos para el diagnóstico de la infraestructura física educativa - directrices y requisitos. Recuperado de https://www.gob.mx/cms/uploads/attachment/file/280292/NMX-R-084-SCFI-2015-.pdf

Norma Mexicana (2015b). NMX-R-024-SCFI-2015. Escuelas - supervisión de obra de la infraestructura física educativa- requisitos. Recuperado de https://www.gob.mx/cms/uploads/attachment/file/104638/NMX-R-024-SCFI-2015.pdf

Norma Mexicana (2016). NMX-R-090-SCFI-2016. Escuelas —elementos para la accesibilidad a los espacios de la infraestructura física educativa- requisitos. Recuperado de https://www.gob.mx/cms/uploads/attachment/file/453015/NMX-R-090-SCFI-2016.pdf Norma Mexicana (2018). Normas Técnicas de la Ley de la Construcción del Estado de Tlaxcala. Recuperado de https://periodico.tlaxcala.gob.mx/indices/Ex13042018.pdf 


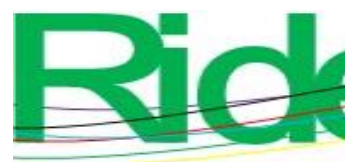

Revista Iberoamericana para la
Investigación y el Desarrollo Educativo
ISSN $2007-7467$

Norma Mexicana (2019). NMX-R-083-SCFI-2019. Escuelas — diseño y fabricación de mobiliario para la infraestructura física educativa - criterios y requisitos. Recuperado de http://www.inifed.gob.mx/doc/pdf/2019/NMX\%20R\%20083\%20SCFI\%202015\%20ESC UELAS\%20DISE\%C3\%910\%20Y\%20FABRICACION\%20DE\%20MOBILIARIO\%20 PARA\%20LA\%20INFRAESTRUCTURA\%20FISICA\%20EDUCATIVA\%20CRITERI OS\%20Y\%20REQUISITOS.pdf

Pacheco, M. (2021). Evaluación del impacto de la infraestructura física educativa en la educación. RIDE. Revista Iberoamericana para la Investigación y el Desarrollo Educativo, 11(22). Recuperado de https://www.ride.org.mx/index.php/RIDE/article/view/940

Pérez, G. (2011). La arquitectura de Juan O’Gorman: una interpretación del paisaje mexicano (tesis de maestría). Universidad Autónoma Metropolitana. Recuperado de https://core.ac.uk/download/pdf/48393639.pdf

Ponce de León, M. y Alarcón, F. (2014). Relación entre los servicios básicos de instituciones educativas escolarizadas y no escolarizadas y los logros de aprendizaje en matemáticas de los niños y niñas de educación inicial en zonas rurales del Perú, Lima. Consorcios de Investigación Económica y Social (CIES)/Grupo de Análisis para el Desarrollo (GRADE). Secretaría de Educación Pública [SEP] (2019). Lineamientos para la formulación de indicadores. Secretaría de Educación Pública. Recuperado de https://www.planeacion.sep.gob.mx/Doc/estadistica_e_indicadores/lineamientos_formula cion_de_indicadores.pdf

Simont, S., Evans, G. and Maxwell, L. E. (2007). Building quality, acedemic achievement and self - competency in New York City public school. In Knapp, E. Noschis, K. and Pasalar, C. (eds.)., School building design and learning performance with a focus on schools in developing countries: Proceedings of the 12th Architecture and Behaviour Colloquium, Lausanne, $\quad$ Switzerland (pp. 41-50). Retrieved from http://www.coe.uga.edu/sdpl/HTML/SchoolBuildingDesign\&LP.pdf

Temple, P. (2007). Learning Spaces for the 21st Century: A Review of the Literature. Center for Higher Education Studies, Institute of Education, University of London. 